\title{
A review on solid riveting techniques in aircraft assembling
}

\author{
Hongwei Zhao ${ }^{1,2}$, Jiangjing $\mathrm{Xi}^{2,3}$, Kailun Zheng ${ }^{4,}$, Zhusheng Shi ${ }^{3}$, Jianguo Lin ${ }^{3}$, Kamran Nikbin ${ }^{3}$, \\ Shihui Duan ${ }^{2}$, and Binwen Wang ${ }^{2}$ \\ ${ }^{1}$ Department of Mechanical Engineering, Xi'an Jiaotong University, Xi'an 710000, People's Republic of China \\ 2 Aircraft Strength Research Institute of China, Xi'an 710065, People's Republic of China \\ ${ }^{3}$ Department of Mechanical Engineering, Imperial College London, London SW7 2AZ, UK \\ 4 Department of Mechanical Engineering, Dalian University of Technology, Dalian116024, People's Republic of China
}

Received: 9 October 2020 / Accepted: 11 November 2020

\begin{abstract}
Solid riveting is the most widely used joining technique in aircraft assembly, and the current key problems affecting practical application and reliable lifting are concentrated on static strength and fatigue. This paper aims to present a practical review on current practice and novel techniques of solid riveting for aircraft applications in order to obtain a thorough understanding of the underlying mechanisms of defect development to assist industrial users to find pragmatic solutions for safe life extension of components. At first, the current status of solid riveting processes is reviewed, and the key influencing factors on static/fatigue failure of riveted joints are identified. Effects of solid riveting design parameters, manufacturing parameters, residual stress, load transfer and secondary bending on static and fatigue strengths of riveted lap joints are discussed, followed by a review of the state-of-the-art solutions that deal with static/fatigue failures. Furthermore the new development in solid riveting techniques, including the use of different materials and riveting processes, is addressed. Finally, future research perspective and applications industrial riveting is presented.
\end{abstract}

Keywords: Solid riveting / joining / static strength / fatigue strength / process parameters

\section{Introduction}

Aircraft is an extremely complex system consisting of a variety of structures with different materials, shapes and dimensions. The structures relevant to a joining process include the nose, rear fuselage, empennage and the wings. These parts need to be assembled during the final stage of production. In addition, for individual component such as wing structure normally at large-scale and with complexshaped geometries, which are unable to be manufactured from a single sheet, that need to be joined together. Different segments need to be manufactured and joined at the first instance and further connected structurally at the final point. Due to the characteristics of material, shape and service requirements, various robust and reliable joining techniques have been developed. Riveting, bolted connections and adhesive bonding are the three dominantly used joining techniques in the current aircraft body structure $[1,2]$. Figure 1a shows examples of detailed applications of these three techniques in a modern aircraft. The quality of joint and assembly, directly affecting the

\footnotetext{
* e-mail: zhengkailun@dlut.edu.cn
}

fatigue resistance, static stress corrosion resistance and reliability of an aircraft, is highly dependent on the used joining techniques.

Due to the stringent requirements and service environment of aircraft, conventional welding technique is not applicable for aircraft assembly due to the material limitation, non-disassembly and high cost \& difficulty of inspection and maintenance [1]. Bolted connection, as a popular cold-mechanical joining, is extensively used in the joining of large-scale structures, like wing \& body. Such a joining technique exhibits the advantages of easy disassembling and maintenance. However, its application is limited resulting from the huge weight increase and corrosion defects occurring in the clearance between bolts and sheets [2]. Adhesive bonding is a competitive technique for joining structure due to the merits of lightweight, high corrosion, fatigue and crack resistance, and good sealingability. It is a typical lightweight joining technique and has been used in aircraft assembling since 1945 [2]. However, the problems of uneven tear strength, unstable bonding quality and aging of adhesives have not been fully addressed [3-5]. In comparison, riveting has dominant advantages in many aspects including stability, long life, high reliability, simple production process \& high efficiency, low cost, and high connection strength [6]. 


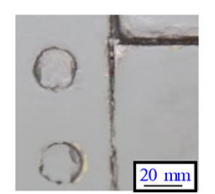

Auto-drilling Riveting

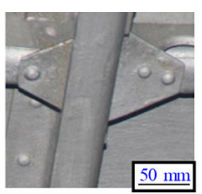

Electromagneic Riveting (Interior Spars or rib)

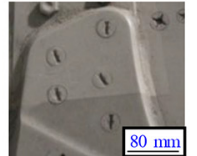

onded(Vertical tail/ fuselage)
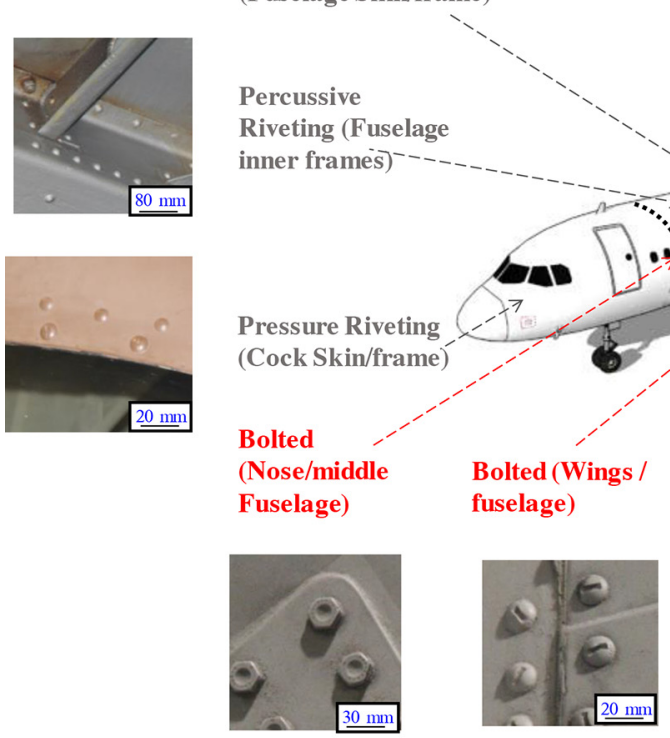

(Interior Spars or rib)
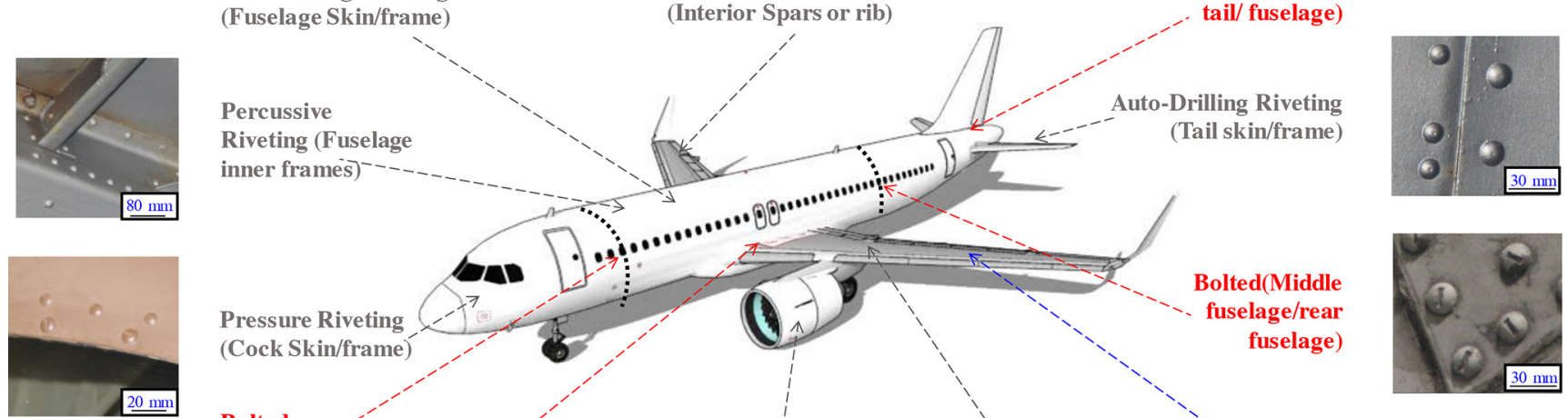

Electromagneic Riveting
(Skin/ interior frame)
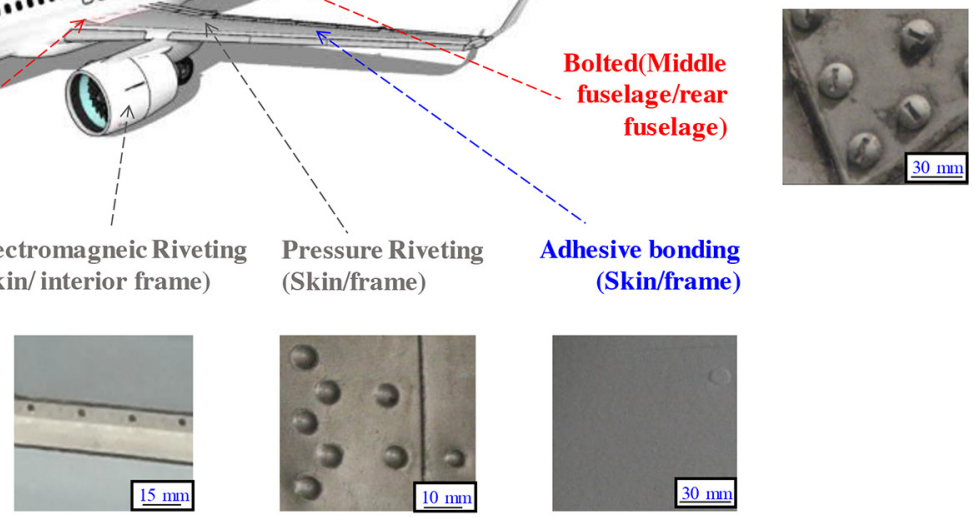

(a)

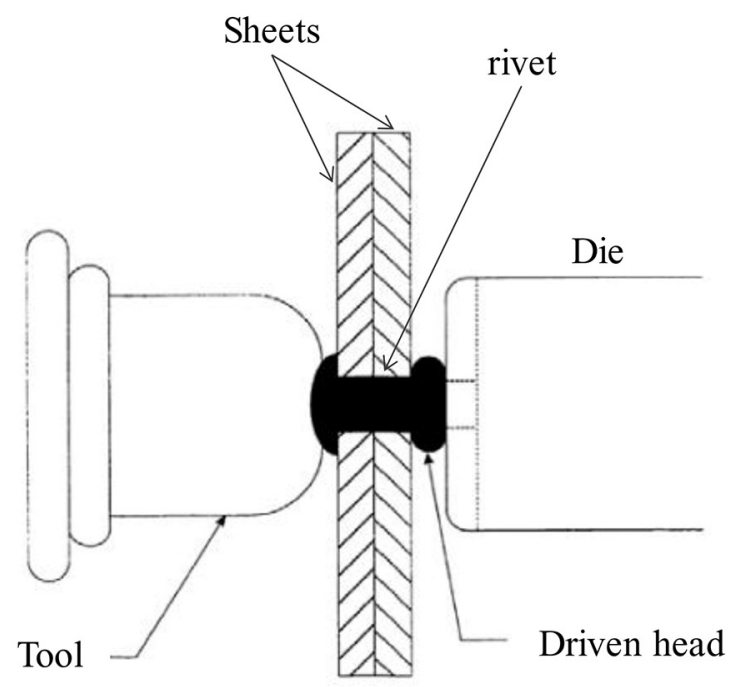

(b)

Fig. 1. Commonly used joining techniques in an aircraft assembly. (a) Joining applications in an aircraft. (b) Schematic of the rivet installation [7].

To date, riveting is still the main method of connection in those structures for aircraft assembling as shown in Figure 1a. In some particular scenarios, adhesive bonding and riveting technique can be combined to improve the connection strength, such as sheet-sheet bonding-riveting between fuselage and skin, bonding-riveting in panelframe-skin jointing, and sheet-stringer in empennage-wing panel [6].
As shown in Figure 1a, the riveting technique is widely used in the connections of structures, such as wing/ fuselage skin and interior frame. Figure 1b illustrates the schematic of riveting process. Basically, riveting belongs to a forging process that used to join the structures together using a metal part called a rivet. The straight metal pin is connected through the adjacent surfaces. Then both ends are formed over the connection enabling 
Table 1. Current in-use typical riveting technologies in an aircraft.

\begin{tabular}{|c|c|c|c|c|}
\hline Automation & Method & $\begin{array}{l}\text { Presence } \\
\text { (roughly) }\end{array}$ & $\begin{array}{l}\text { Advantages \& } \\
\text { - Disadvantages }\end{array}$ & Application \\
\hline \multirow[t]{2}{*}{ Manual } & Hand riveting & $\mathrm{N} / \mathrm{A}$ & $\begin{array}{l}>\text { Convenient } \\
\text { - Poor stable quality }\end{array}$ & $\begin{array}{l}\text { All kinds of riveting } \\
\text { structures }\end{array}$ \\
\hline & $\begin{array}{l}\text { Percussive } \\
\text { riveting }\end{array}$ & 1900s [10] & $\begin{array}{l}\text { Convenient } \\
\text { - Poor quality stability } \\
\text { - Low efficiency } \\
\text { - High noise }\end{array}$ & $\begin{array}{l}\text { All kinds of riveting } \\
\text { structures, even not } \\
\text { open and more } \\
\text { complex structures }\end{array}$ \\
\hline Automation & $\begin{array}{l}\text { Electro-magnetic } \\
\text { riveting }\end{array}$ & 1970s [16] & $\begin{array}{l}>\text { Uniform riveted interface } \\
>\text { High fatigue life } \\
>\text { No need for finishing holes } \\
\text { and large tonnage riveting press } \\
>\text { Small workpiece deformation } \\
\text { - Complex equipment } \\
\text { - Short life and big noise }\end{array}$ & $\begin{array}{l}\text { Titanium alloy, Alloy steel, } \\
\text { Composites }\end{array}$ \\
\hline
\end{tabular}

the structures to be joint securely. The forging force is exerted through various approaches, such as hammers, punch and even electromagnetic setup [8]. For modern riveting in the aircraft industry, a variety of riveting techniques can be seen. For a specific process, the characteristics may induce different kinds of defects, such as micro-crack, corrosion and static failure, under different service conditions, for example, the large tension of skin in high-speed flight, and the fatigue of structure under cyclic loading. In terms of developing a specific riveting process to connect various structures, the final connection quality is determined by various factors, such as design parameter, production variables, residual stress, load transferring, secondary bending (SB). These factors bring huge uncertainties to production and FE simulation results.

To obtain a thorough understanding of riveting defects and aid aircraft industries to identify solutions, this article gives a comprehensive review on the latest research progress of the solid riveting techniques mainly in the aircraft industry. Firstly, the riveting method development for aircraft assembly are introduced and characteristics and limitations of individual methods analysed. Based on the analysis, key practical techniques are reviewed in detail including latest progress of theory, experimental investigations. Finally, conclusions and recommendations for future research are presented.

\section{Development of riveting technologies in the aircraft industry}

\subsection{Riveting techniques in aircraft assembly}

Riveting technologies have been developed over 150 years. The first application in literature was found in experiments conducted by Eaton Hodgkinson for the strength of wrought-iron plates [9], which nowadays is still a dominant connection technology in various industries. Basically, the riveting technologies can be divided into traditional and advanced riveting technologies characterised by the degree of used automation. The traditional riveting technologies include hot riveting [9], percussive riveting [10], wobble riveting [11], pressure riveting [12] and interference-fit riveting [13] with human labouring playing the dominant role during riveting. Advanced riveting technologies, such as electromagnetic riveting and auto-drilling riveting, driven by the requirements of connecting complex structure and new material, no-rivet riveting was developed aided by the introduce of automation [8]. Through the precise automation, the uncertainties and errors generated from human operations in the traditional riveting technologies can be minimised.

The first introduction of riveting technology in aircraft industry may be found in reference [14] for connecting aluminium alloys in 1920 . Table 1 summarises the current 


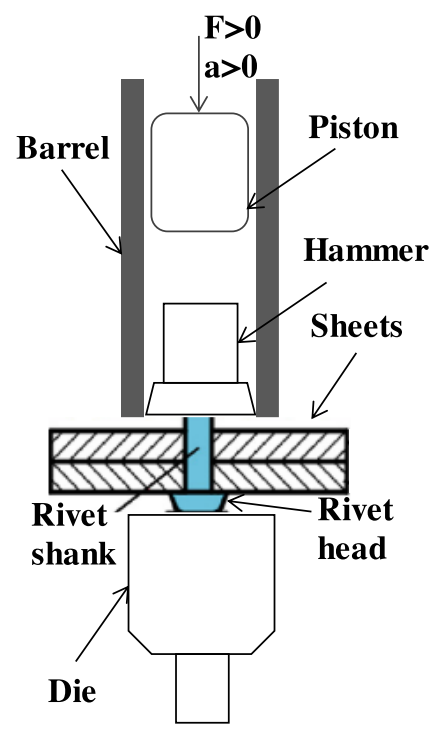

(a)

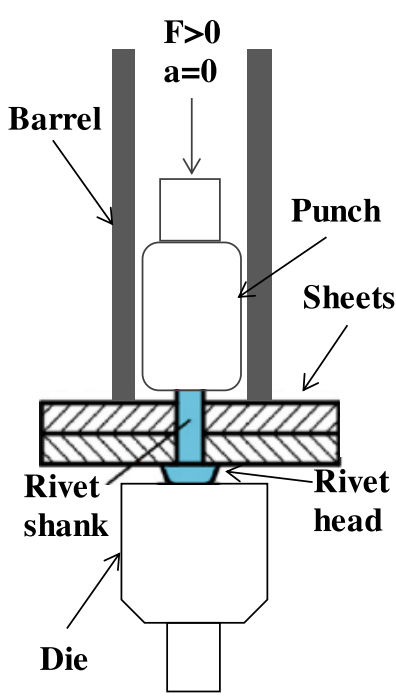

(b)
Fig. 2. Schematic of operation principles of traditional riveting technologies. (a) percussive riveting (b) pressure riveting.

commonly used riveting technologies in aircraft assembly including both traditional and advanced riveting technologies. For traditional riveting, hand riveting, percussive riveting and pressure riveting have already been successfully used for structures such as fuel tank, airtight cockpit due to the advantages of low cost and convenience. Figure 2 shows the schematic of operation principles of percussive and pressure riveting, which are typical technologies for aircraft applications. Percussive riveting is probably the most widely used process in aircraft assembly and manufacture [10]. During percussive riveting (Fig. 2a), the rivet is plastically deformed by the compressive force exerted from the hammer inside rivet gun to form a drive head on the die surface. Percussive riveting requires the gun piston to hit the hammer several times, which produces noise, and the riveting quality is poor due to the limited squeeze force. While for the pressure riveting process, the punch and rivet continuously contact and the compressive force is exerted by a hydraulic system to upset the rivet shank homogeneously. Then, the shank diameter expands into the hole wall and squeezes with the sheets, resulting in a hole expansion. This process ends with a standard driven head including height and diameter. Compared to percussive riveting, pressure riveting requires a larger squeeze force, given by the pressure riveting machine gradually. Therefore, the riveting quality is better. However, the size of riveting machine constrains the process only applicable for open-type structures. The main characteristic of above traditional technologies is that riveting process is still partly or entirely relied on human operation and the riveting equipment is bulky. Nowadays, these traditional riveting technologies still have certain applications in modern aircraft industry, while their usage are already greatly reduced due to the obvious limitations summarised as follows:
- The absence of automation results in low productivity and relatively high manufacture cost. The dependence on the skill \& experience of engineers may induce inconsistent joint quality. In addition, the slug rivet for various applications cannot be riveted through traditional riveting technologies.

- New robust materials for aircraft structures, especially for titanium alloys, are being involved due to the excellent properties of high strength, low density and good corrosion resistance [6]. In addition, large-scale structures are designed for modern large-capacity aircrafts. Both the new material and structures cannot be riveted using traditional technologies.

- The connection strength is insufficient as inhomogeneous interference in the thickness direction exists. The nonuniform interference is unable to be improved using the traditional riveting.

- To address the above limitations of traditional riveting technologies, advanced riveting technologies, such as auto-drilling riveting [15] and electromagnetic riveting [16], have been introduced, whose operation principles are schematically shown in Figure 3. The automatic drilling and riveting machine enables to automatically measure and adjust the perpendicularity between the feed direction and the work-piece before clamping and drilling, as schematically shown in Figure 3a.

The Electromagnetic Riveting (EMR) technology is significantly different from other riveting processes, as the riveting force comes from the Lorentz Force. During the EMR progress, firstly, capacitors in the set-up are charged to a certain voltage. During the discharge process, the high-amplitude alternative current runs through the flat spiral coil embedded in the mold. Simultaneously, an induced eddy current generates in the driver plate. These two opposite currents induce magnetic field. Then the force originated from the repulsive force between the two magnetic fields acts on the punch to compress the rivet in the form of stress wave through the driving head, which leads to a finished rivet at a high-speed loading rate.

During the EMR process, the rivet shaft experiences upset deformation to form the rivet tail to lock the two sheets. EMR is introduced to provide high speed and large squeeze force to conduct riveting without damage $[13,15,16,18]$. In recent years, EMR is largely developed due to a wider application in the aircraft assembling and manufacturing, as summarised in Table 1 . The advantages of advanced riveting technologies are summarised as below:

- Automation enables to minimise the operation error and production inconsistency occurred in traditional riveting technologies.

- The auto-drilling riveting is introduced for addressing homogeneous interference-fit by symmetrical squeezing at both ends to drive rivet head.

- The EMR enables to connect new materials, such as titanium alloys and composites due to larger squeeze force and high squeezing speed. 


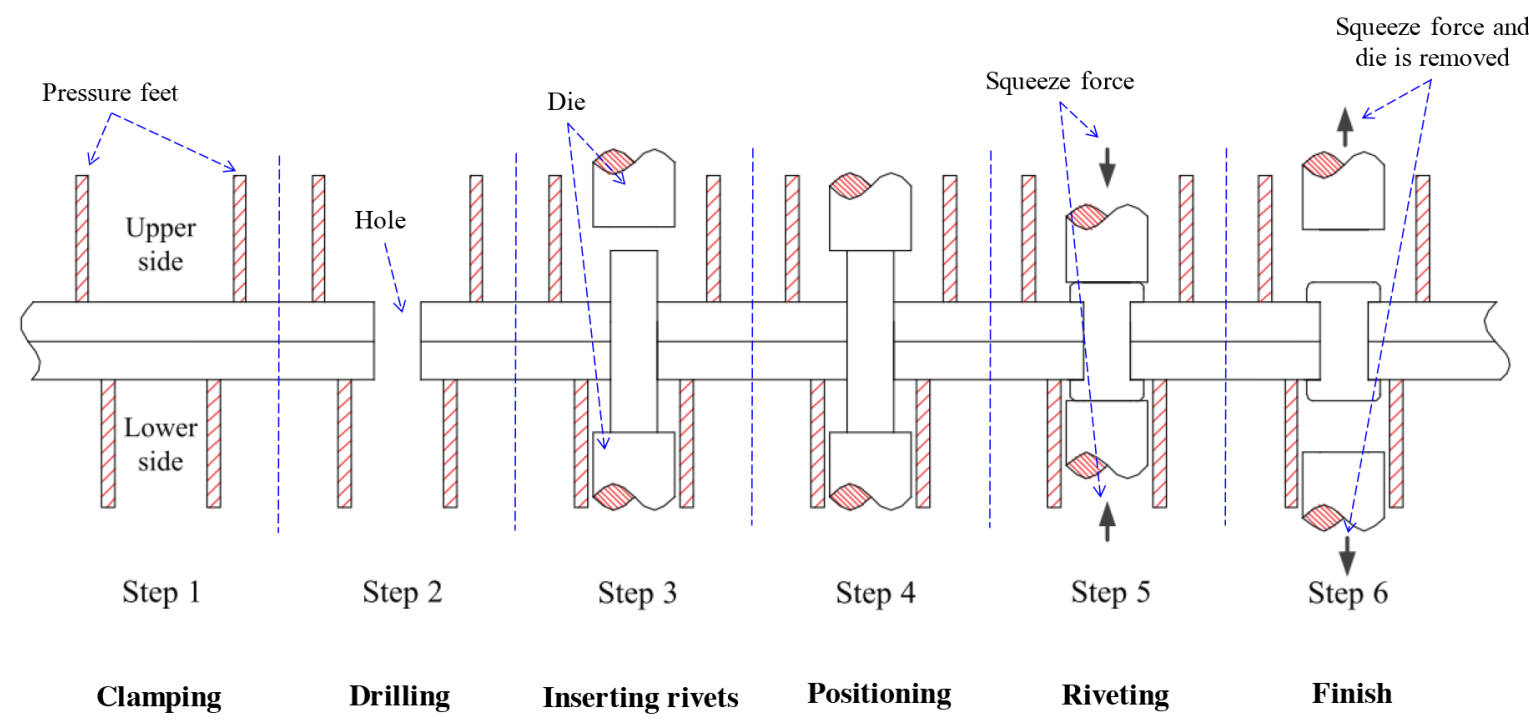

(a)

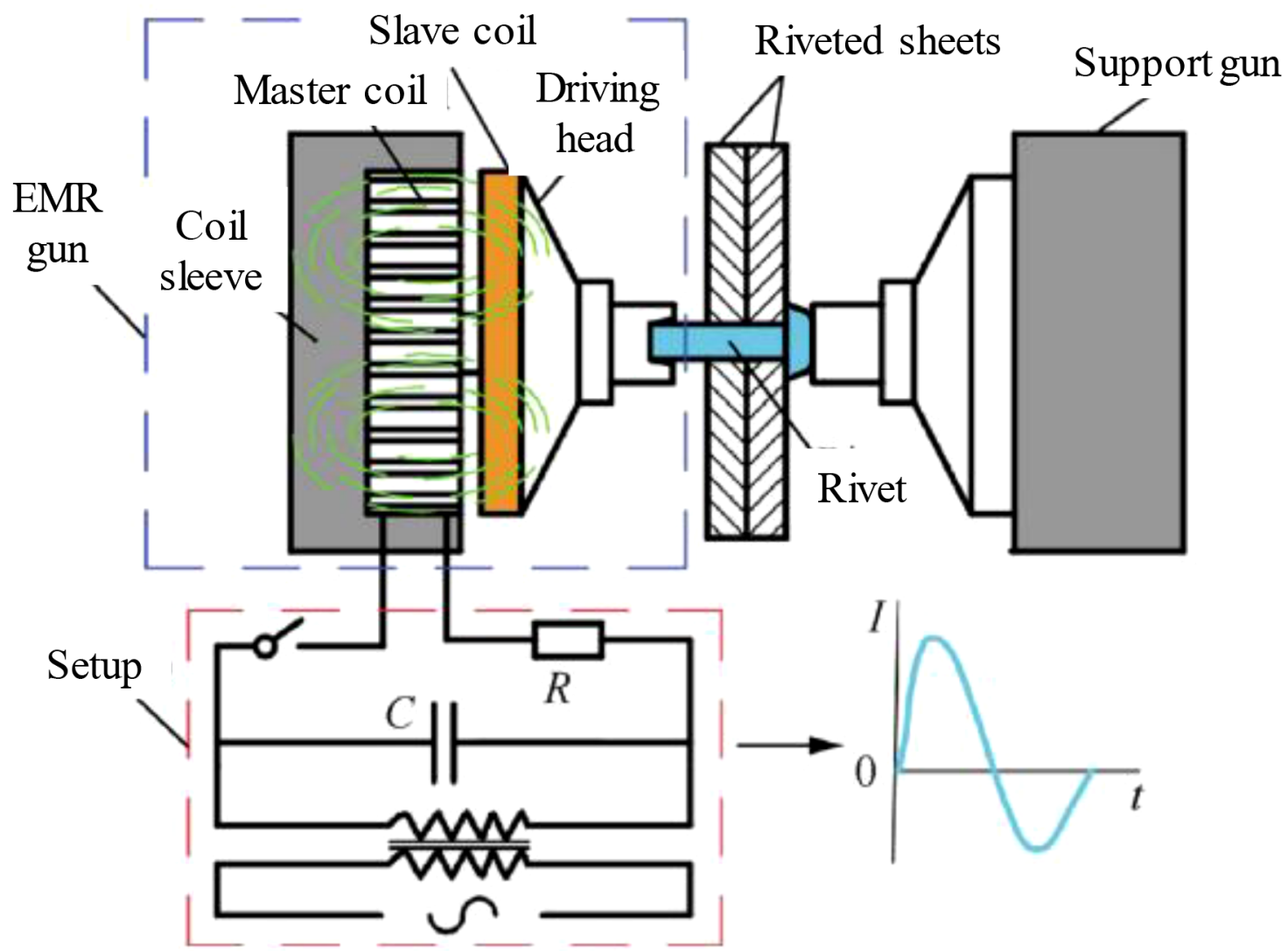

(b)

Fig. 3. Schematics of the operation principles of advanced riveting technologies. (a) auto-drilling riveting [17], (b) electromagnetic riveting [16].

\subsection{Design of riveting process}

A riveting technique is chosen for connecting specific structures based on structure characteristics and materials as discussed in the previous section. Therefore, the riveting needs to be precisely designed before use. Essentially, the rivet joint belongs to a kind of local connection, while in terms of practical application at large-scale, a vast of rivets need to be used together to achieve a reliable connection between two structures. Therefore, correlations between 
Unqualified due to uncertainties

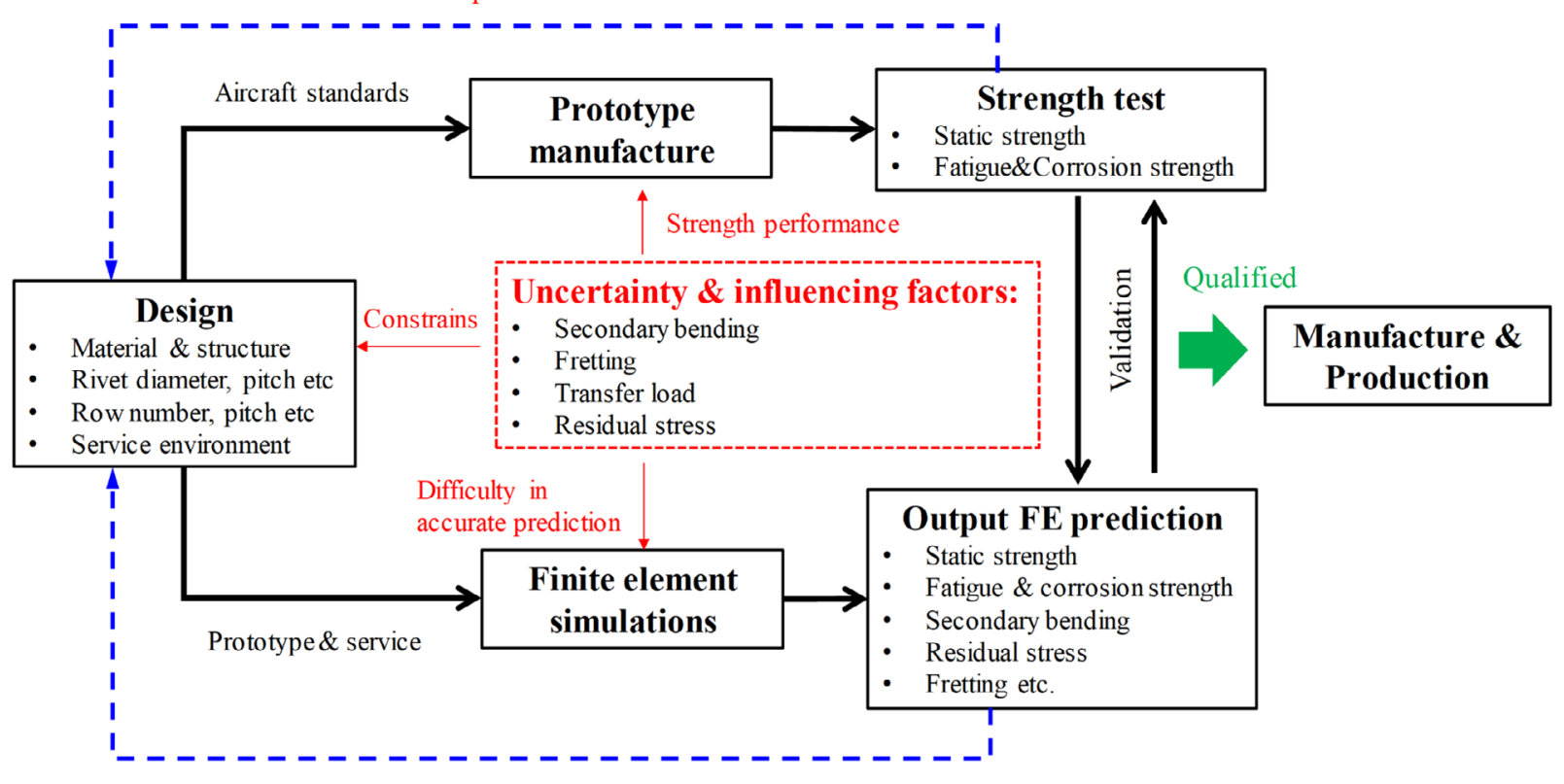

Optimisation if unqualified

Fig. 4. Overall development routine of applying a riveting technology from initial design to final production.

neighboring rivets, such as pitch and row number, also need to be considered. The overall development routine of applying a riveting method from initial design to final manufacture is given in Figure 4. The whole routine is composed by sections of local \& integrated design, prototype manufacture, sample manufacturing, verification, optimisation and improvement. For the design of a local rivet connection, influencing factors such as rivet type (protruding head, flush head or blind head), material, and dimension, need to be considered. In addition, the overall layout of using a series of local rivet connections also needs to be designed.

The variables of overall layout of rivet joints, as schematically shown in Figure 5, consist of the number of rivets, layout patterns (in-line), the number of riveting rows, row spacing, rivet pitch, and the distance to the edge of structure. The above variables can be summarised as design parameters. These geometric influencing factors exhibit significant influences on the connection performance. For instance, (i) the rivet type affects the uniformity of hole expansion along the thickness direction. The protruding head rivet brings better homogeneity for hole expansion than the countersunk head rivet [19]; (ii) the diameter and number of rivets have significant influences on the static strength behaviour of riveted lap joints [20]; (iii) the rivet material has great influence on the load transfer as the deflection depends on the riveted material [20]; (iv) the number of rivet rows, row spacing and sheet thickness affects secondary bending of the connected sheets [20,21]; (v) the length of rivet corresponding to the extent of part of rivet material that is squeezed into rivet hole to make the hole expand by the squeeze force has significant effects on the residual stress $[20]$.

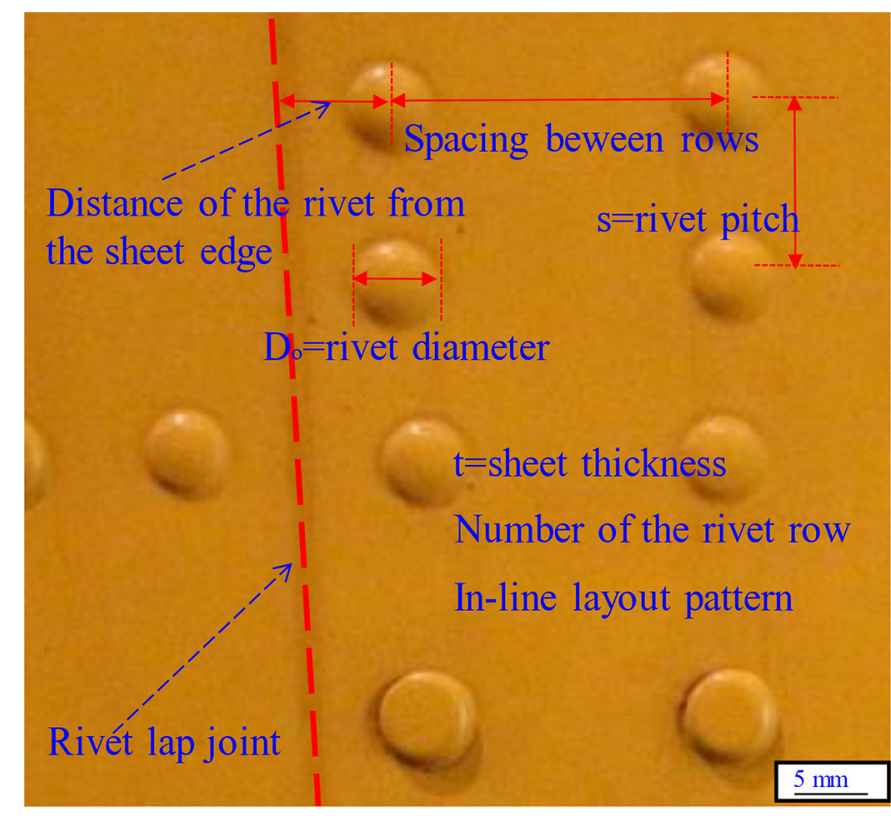

Fig. 5. Example of design parameters for riveted lap joint in the aircraft structures, Practical example in fuselage skins of an aircraft [22].

Once the design stage is finished, a prototype of these rivet connections needs to be manufactured and tested subsequently. During the manufacture, the squeeze force governing the plastic deformation of rivet is the key variable which determines the rivet head dimension (length and diameter), the rivet shank thickness (plastic deformation), hole expansion, the residual clamping force of two sheets, the contact between rivet and hole wall, the contact 


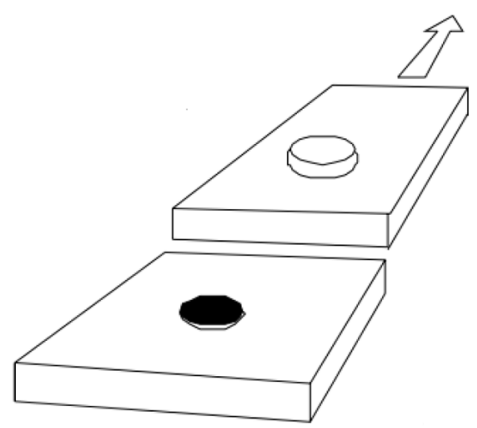

(a)

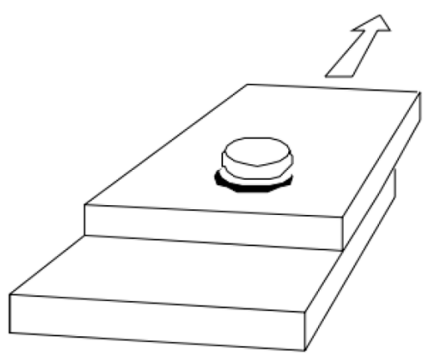

(b)

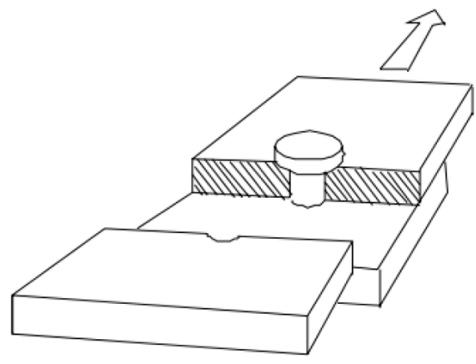

(c)

Fig. 6. Commonly seen static failure modes in riveted lap joints, (a) rivet shear, (b) hole bear and (c) sheet bear [23].

between driven head and bottom sheet, the contact between manufactured head (protruding head or flush head rivet) and upper sheet. Such features after riveting induce different uncertainties including residual stress, fretting and load transfer which affects the strength performance of the assembly. The individual correlations between rivet feature and the induced deteriorations are summarised briefly as follows:

- The residual stress existing in the rivet shank and sheets directly results from the diameter of rivet shank and hole expansion.

- The interface friction for various contacts could occupy a part of the load affecting load transfer and static strength during service.

- The interface friction could also induce fretting which potentially results in corrosion problems.

- SB contributes to stress concentration due to bending stress produced at the edge of overlap for riveted lap joint.

Therefore, the load transfer, SB, residual stress and fretting could result in high-stress concentration leading to static failure and fatigue (including corrosion fatigue) failure of both the prototype and practical riveted structures.

To evaluate the performance of rivet joints, these strength properties of the prototype need to be tested before proceeding to production. However, the rationality and validity of a riveted joint design cannot be fully verified by tests due to the huge number of uncertainties, insufficient measurement capability and extremely high expense. Tests can only provide synthetic static and fatigue test results. Therefore, in the meantime, finite element (FE) simulation is also used by the design department to numerically calculate the riveted structure performances during service. The computed results can be validated by physical test results to verify its rationality and effectiveness. Then, the reliable FE model could be further improved and used for optimising the designs of reverted joints. It should be noted that, to establish an accurate and reliable FE model, the previously mentioned influencing factors (SB, fretting, load transfer \& residual stress), and even some unknown factors (such as the embrittlement of the hole edge due to riveting) must be precisely modelled. The underlying correlations between these factors and resultant strength performances and defects must be thoroughly known.

\section{Defects and failure mechanism in riveting processes}

\subsection{Static failure}

Riveted joint is normally the weakest structure in modern aircraft assembly. Therefore, static failure of riveted joint has always been the key concern for aircraft engineers. Particularly, with increasing applications of fiber metal laminate, lightweight alloys and composites in the aircraft structures, unprecedented challenges have been brought to static failure. Static failure of riveted lap joints represents the behaviour of structural damage under ultimate static loads. The commonly seen static failure modes can be classified into rivet shear, sheet tension, hole bearing failure [23], as schematically shown in Figure 6.

During the service of a flight, the riveted lap joint unit experiences various loading conditions, mainly tensile and shear loading resulting from the cabin pressurisation [22]. Basically, the static failures of a joint occur when the joint is unable to sustain the applied load (ultimate load). The specific type of static failure in joints depends on the sustained loading condition and the joint configurations; individual failure mechanism is illustrated as follows:

- Rivet shear: The rivet was cracked horizontally due to the large shear stress. The reasons can be attributed to the small diameter of rivet, insufficient number of rivet and lack of interface friction to compensate for the shear stress. Then each individual rivet sustains a greater load and. and the rivets are very easy to be cut off when the shear stress exceeds the maximum value, as schematically shown in Figure 6a.

- Hole bear: Hole bear defect is easy to occur due to the lower stiffness of sheets, the embrittlement of the sheets or insufficient hole expansion produced by squeeze force, as schematically shown in Figure 6b.

- Sheet bearing: The cross-section area near the drilled holes is smaller than the other areas. The material here is prone to break under the tensile stress resulting from the in-plane tension of the structure, as schematically shown in Figure 6c. 

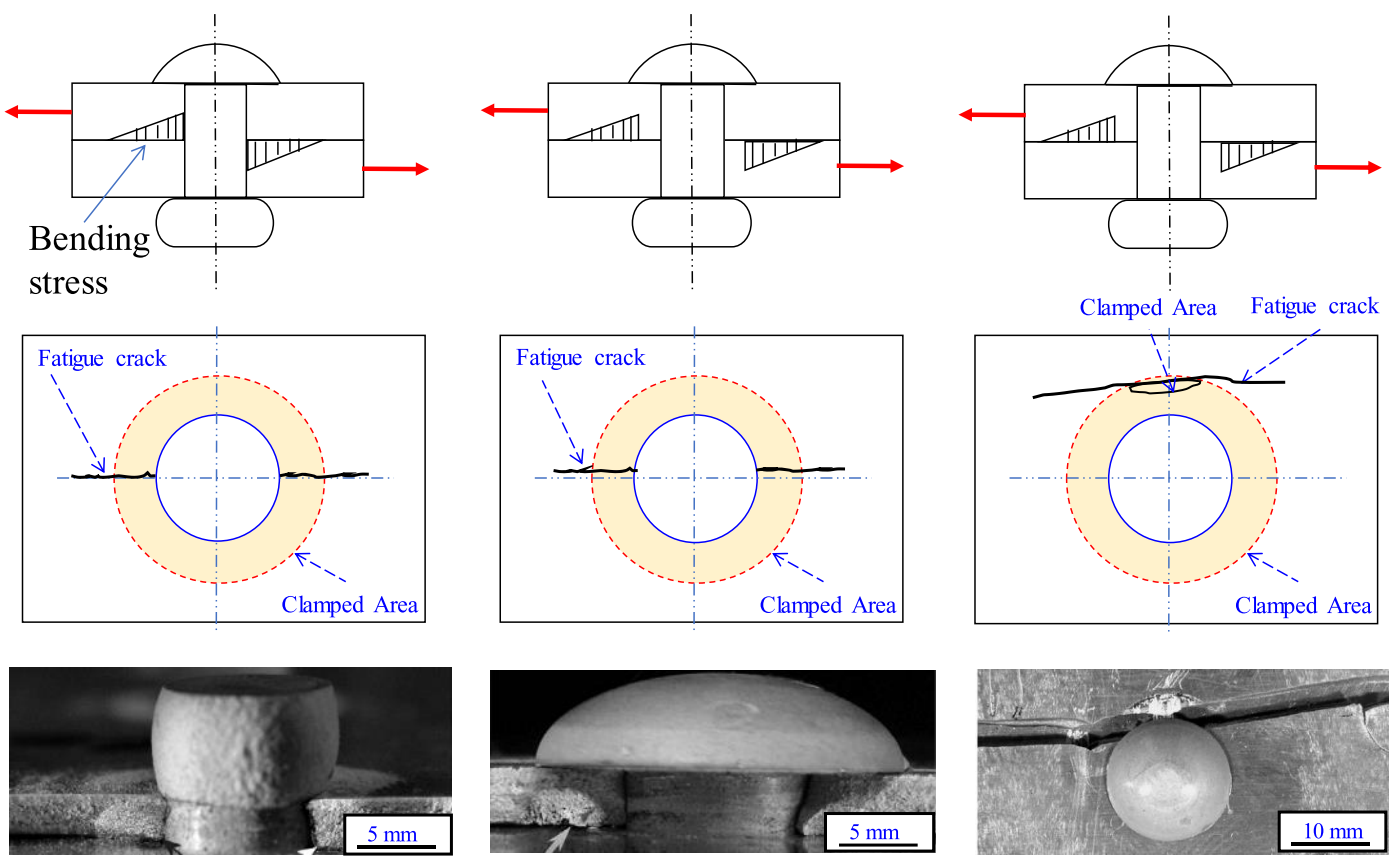

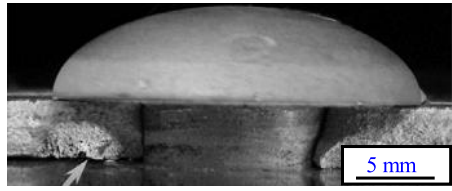

(b)

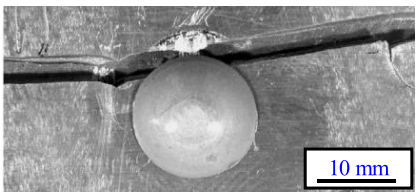

(c)

Fig. 7. Common mode of fatigue crack in the riveted lap joints. (a) at the hole edge (b) outside the hole (c) above the hole.

Generally, the static performance of a riveted joint is normally determined by the joint design, manufacture and sustained stress state in service. The static failures mentioned above are directly related to the influencing factors, that is, residual stress, SB, friction between connected sheets and load transfer, which depends on the initial design of rivet joint. It should be noted that each static failure is normally induced by the combined effects of various uncertainties. The underlying correlations need to be thoroughly investigated to guarantee an accurate rivet joint design initially.

\subsection{Fatigue failure}

Driven from the goals of safety and economic, the fatigue failure has gained an increasing attention among aircraft engineers in modern aircraft industry. The more pertinent designs need to be made:

- Driven by the economic objective, the design life-cycle of an airplane has increased significantly, thus the rivet lap joints require a longer fatigue life.

- Driven by the lightweight objective, the dimensions of rivets need to be decreased as much as possible, resulting in the increase of sustained stress levels.

- Driven by the safety objective, damage tolerance requirements for riveted lap joints must be satisfied carefully.

The riveted joint is prone to fatigue failure under cyclic loading. Figure 7 summarises the three types of fatigue failures attributed to different uncertainties.

Crack at hole edge: the crack initiation in the minimum cross-section of the sheet at the edges of hole or at the end of countersink is found for snap and countersunk rivets, when the clamping force is limited and a very small part of the load is transmitted by friction between the sheets, as shown in the Figure 7a. Actually, the failure is caused by the fact that the upper and lower sheets are not in the same straight line, the sheet is subjected to SB besides the shear force subsequently, which results in a larger fatigue stress near the edge of riveting joint, and fatigue is easy to generate and expand here.

Crack outside of the hole: the crack nucleation shown in Figure $7 \mathrm{~b}$ is a consequence of modified residual stress distribution and improved clamping obtained by a larger squeezing of the rivet. Then the residual tensile stress in the circumferential direction around the hole, inducing decohesion of the material, movesa short distance away from the hole edge. In the mean time, the rivet heads increase the flexural rigidity of the joint locally. Bending due to local eccentricity is restrained underneath the rivet heads and maximum bending moment occurs at the outer edge of the rivet head. Due to the above factors, the site of the maximum local tensile stress moves away from both the hole edge and the overlap section.

Crack above the hole: the initiation and propagation of crack occur above the hole as shown in Figure 7c, keeping extremely high clamping force for well-driven rivets. The material around the rivet hole, together with the rivet itself, acts as a single continuous piece of material. The nature of the load transmission has changed from a pinloaded hole type to a contact zones type. The maximum concentration occurs ahead of the rivet hole where SB and fretting corrosion cooperate to initiate fatigue crack nuclei. The crack starts at the top of the fretted zone, generally at some neighboring locations, and no longer grows through the hole. 


\section{Research on static/fatigue strength of riveted lap joints}

\subsection{Static strength in traditional riveting}

In recent years, research on static strength of riveted lap joints mainly focuses on influencing factors of traditional riveted joints and new riveting structure including rivetedbonded hybrid joint and riveting structures using electromagnetic riveting.

Most of studies have focused on the influence of squeeze force on residual stress/strain distribution and SB stresses after rivet installation. Huan et al. [24] conducted experiments of single-row countersunk riveted lap joints to investigate the squeeze force effect on static behaviour of the riveted lap joints. The joint stiffness became nonlinearly smaller with the gradually increased tensile load, while the effect of squeeze force on joint stiffness was not significant. However, larger squeeze force caused smaller joint static strength. The reason is that greater squeeze force introduces greater residual stress around the hole, and the maximum principal stress around the hole becomes tensile stress instead of initial compressive stress. Subsequently, the static strength becomes weaker.

Squeeze force is the key factor affecting the quality of joint in riveting. A conclusion in fatigue properties for riveted joints is that larger squeeze force leads to better fatigue performance of joints $[25,26]$. The static fatigue/ strength of riveted joints should be considered comprehensively to define the squeeze force value. The research results show that the static strength of the joint decreases slightly with the increase of squeeze force, while the fatigue properties increase.

Experimental results have delivered qualitative conclusions, but quantitative relationships between squeeze force and static strength are not available yet. At present, the squeeze force is controlled under a fixed value, so the fatigue properties and static strength of the joint need to be balanced. In addition, other influence factors, for example, surface contact, need to be investigated. To date, the influence of squeeze force on joint static strength, load transmission, tendency of stress field around holes, and SB while tensile load applied is still largely unknown.

\subsection{Fatigue strength of riveted lap joints}

Extensive efforts to address fatigue failure of riveted joints have been made, which can be summarised in the following aspects: design parameters, production variables, influenced factors and quantitative research. Figure 8 illustrates the current state of the art for fatigue failure research on riveted joints. Regarding the design parameters, the latest research on the fatigue failure behaviour of riveted joints mainly focuses on rivets, die, sheets and applied loads [27]. Manufacturing variables, including squeeze force, interference fit, riveting deformation, surface condition and friction caused by riveting, have been investigated [28]. Influenced factors derived from design parameters and manufacturing variables greatly affect the fatigue failure behaviour [18]. To address the above factors, quantitative

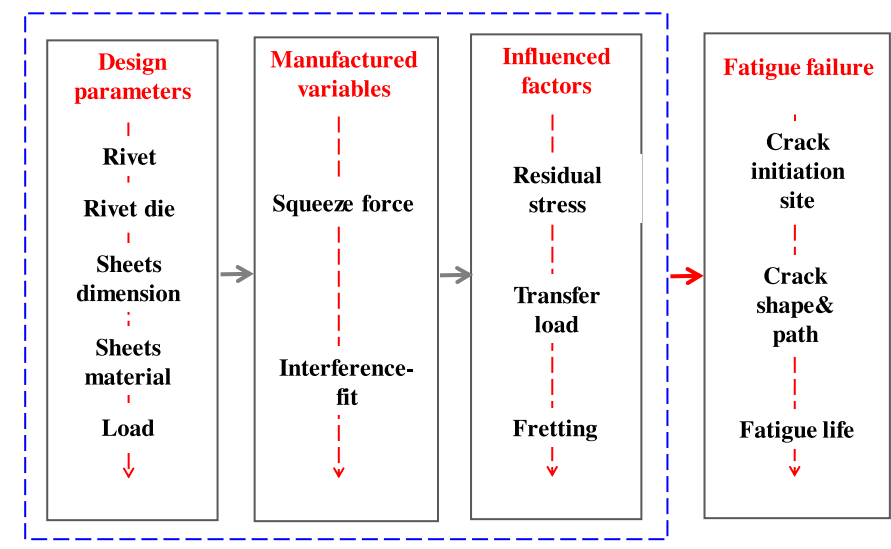

Fig. 8. Overall structure of fatigue failure research on riveted joints.

research is the key approach to solve the current engineering problems, aiming at controlling the abovementioned riveting uncertainties to address fatigue failure, such as the prediction of fatigue properties of joints and the quantitative relationship between factors and fatigue properties [25].

\subsubsection{Design parameters}

\subsubsection{Rivet}

Driven head that affects the fatigue failure behaviour of rivet, is dependent on rivet diameter, length, protruding height and riveting die, resulting in different height and diameter of the driven head. Riveting dies also affect the shape of the rivet head [29]. Researchers pay more attention to the quantitative relationship of such design parameters to characterise the fatigue properties of joints $[13,29]$. In order to investigate the relationship between squeeze force and the ratio of $\mathrm{D} / d(\mathrm{~d}$ is the diameter of rivet before riveting and $\mathrm{D}$ is the diameter of rivet after riveting), Skorupa et al. [30] riveted two strips together by 20 rivets, and obtained the correlation between $\mathrm{D} / d$ ratio and squeeze force of each combination of sheet metal, sheet thickness (t) and rivet type. Normally, squeeze force is used to indicate the hole expansion during riveting as there exists a strong direct proportion correlation [31]. As shown in Figure $9 \mathrm{a}$, for $t=1,1.6$ and $2 \mathrm{~mm}$, the ratio $\mathrm{D} / d$ exhibits a non-linear relationship with the squeezing force, which indicates a similar non-linear correlation to the hole expansion. Therefore, with the increasing of ration $\mathrm{D} / d$, the hole expansion increases which results in a greatly improved fatigue performance under this large squeeze force. It is believed that the fatigue properties of the joint are better for the large $\mathrm{D} / d$ ratio.

Slug rivet has been introduced into aircraft industry and brought greater fatigue properties of riveted joints due to significant improvement of homogeneous hole expansion along sheet thickness. To achieve the riveting of slug rivet, automatic-riveting has been developed in aircraft industry $[17,32]$. Two additional procedure parameters, movement synchronism of the riveting dies and rivet protruding height, need to be taken into account and optimised during 


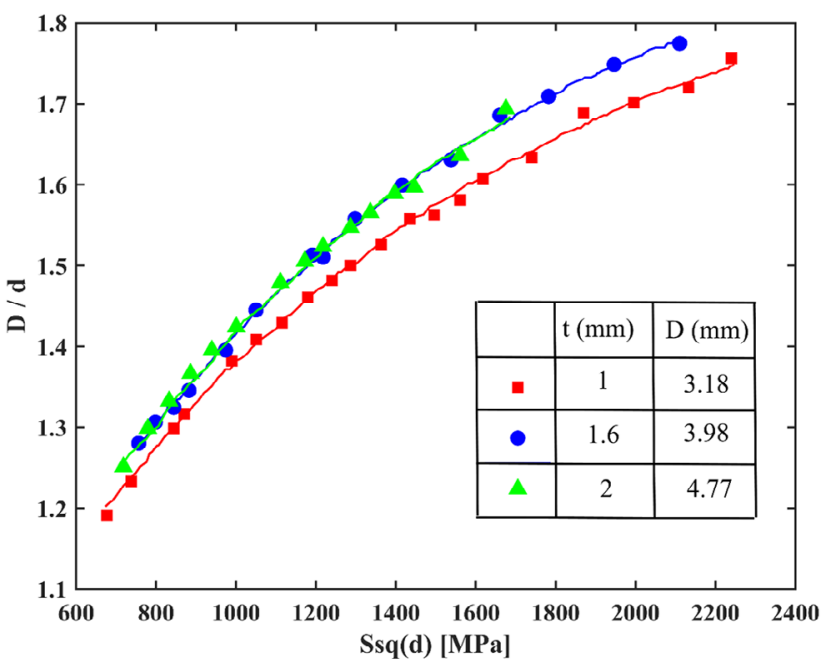

(a)

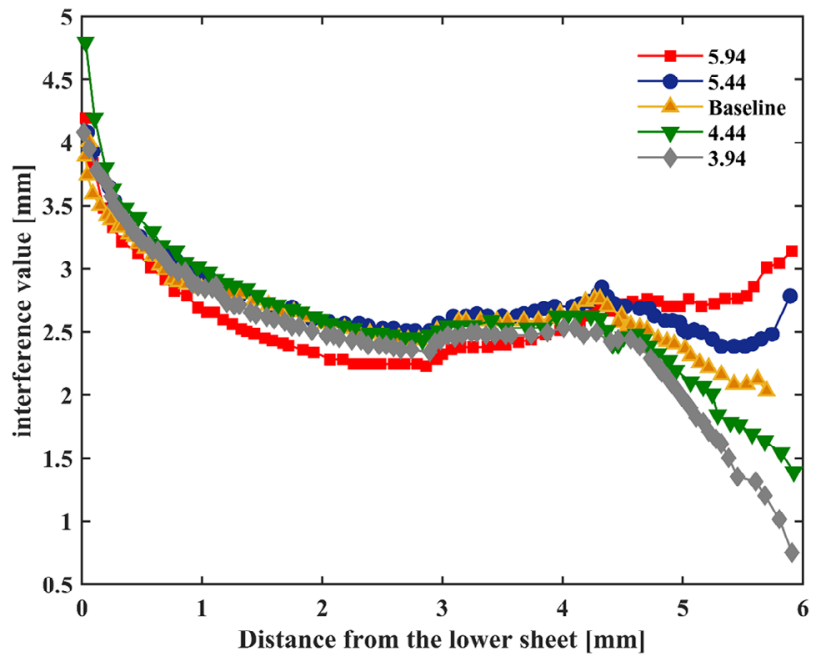

(b)

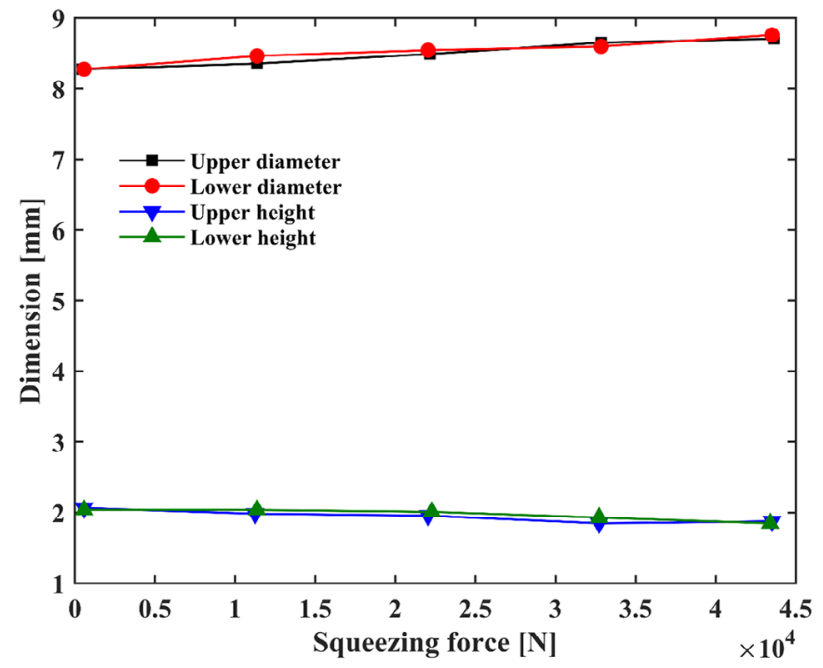

(c)

Fig. 9. (a, b, c) Effects of design parameters of rivet on other parameters. (a) Engineering drawing $\left(\mathrm{S}_{\mathrm{sq}}(\mathrm{d})\right)$ measured at different locations as a function of $\mathrm{D} / d$ ratio for the countersunk rivet $[30]$. (b) The interference distribution conditions obtained from different protruding heights [33]. (c) Driven head dimension with different squeezing forces [17]. rivet installation process, which significantly improved the fatigue performance of riveted joint [33]. As shown in Figure $9 \mathrm{~b}$, except the region in the vicinity of countersunk hole, the interference value and the variation trends of the distribution curves almost remain constant for different protruding height. The influence of countersunk hole on the improvement of riveting quality is insignificant when the protruding height increases. Cui et al. [34] considered that the inclination angle of rivet die has a significant effect on the plastic flow of material, which determines the structure distribution of the forming head, thus affecting the fatigue performance of the joint. While Lei et al. [17] concluded that the dimensions of the driven head after riveting affected fatigue properties of riveted joints. The dimensions of the driven head affect fatigue properties by interference condition, as shown in Figure 9c. The dimension of the driven head is significantly affected by the squeezing force. The curves are nearly a linear function of the applied force. The dimensional measurements of the driven head will allow estimation of the applied squeezing force for quality control of the riveting process with respect to the fatigue performance of the riveted assembly.

\subsubsection{Riveted sheet}

The dimension, material and hole of riveted sheets have great influence on the fatigue performance for riveted joint, as shown in Figure 10. Skorupa et al. [31] carried out fatigue tests of three-row rivet lap joints with different combinations of sheet thickness, rivet squeeze force and interface conditions. It was found that the effect of each of the three test variables on fatigue life depends qualitatively or even quantitatively on the specific combination of the other two variables and the applied stress level. The countersunk hole on fatigue properties of riveted joint has been a research hot spot in riveting [35]. No systematic dependency of hole expansion on the sheet thickness can be observed in Figure 10a, but an obvious increasing trend of hole expansion can be seen evident for each sheet thickness, with the increase of squeeze force. It can be further seen in Figure 10b that hole expansion is always larger in the sheet next to the rivet driven head than that adjacent to the manufactured head [31].

\subsubsection{Applied loading}

Applied loading is also a key factor in joint design due to significant correlation between fatigue failure behaviour and applied loading. Zhou et al. [35] found that fatigue crack initiation locations for joints are dependent on the applied cyclic load range. At low stress levels, the crack initiation and propagation occur somewhere away from the hole edge. When the cyclic stress ranges increase, the fatigue cracks occur at the hole edge and tends to propagate across the middle plane of the hole.

\subsubsection{Production variables}

The production variables mainly include squeeze force and interference fit, and research on their correlations with fatigue properties will be discussed in this section. 


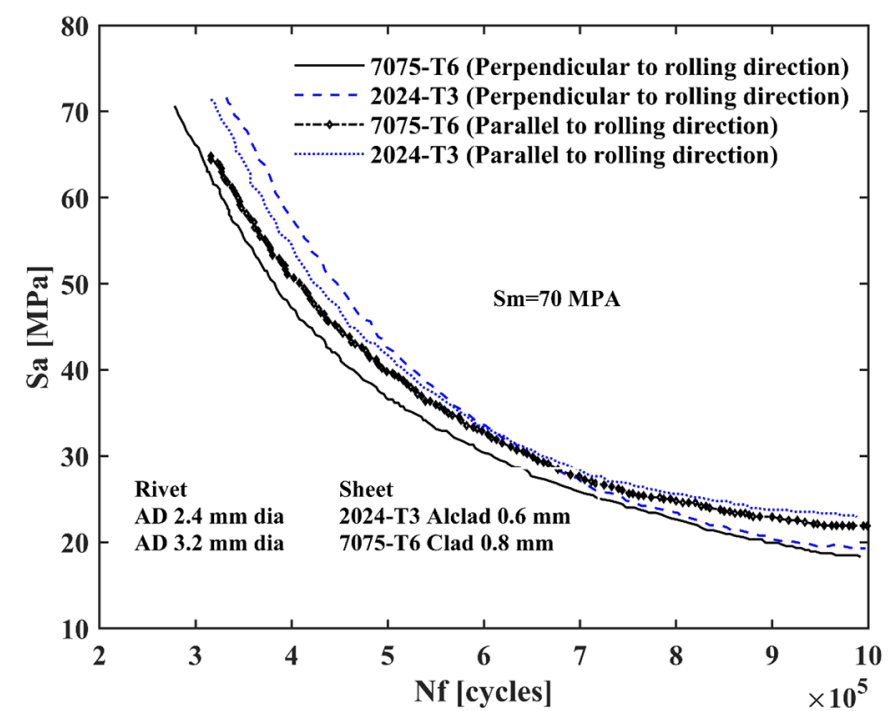

(a)

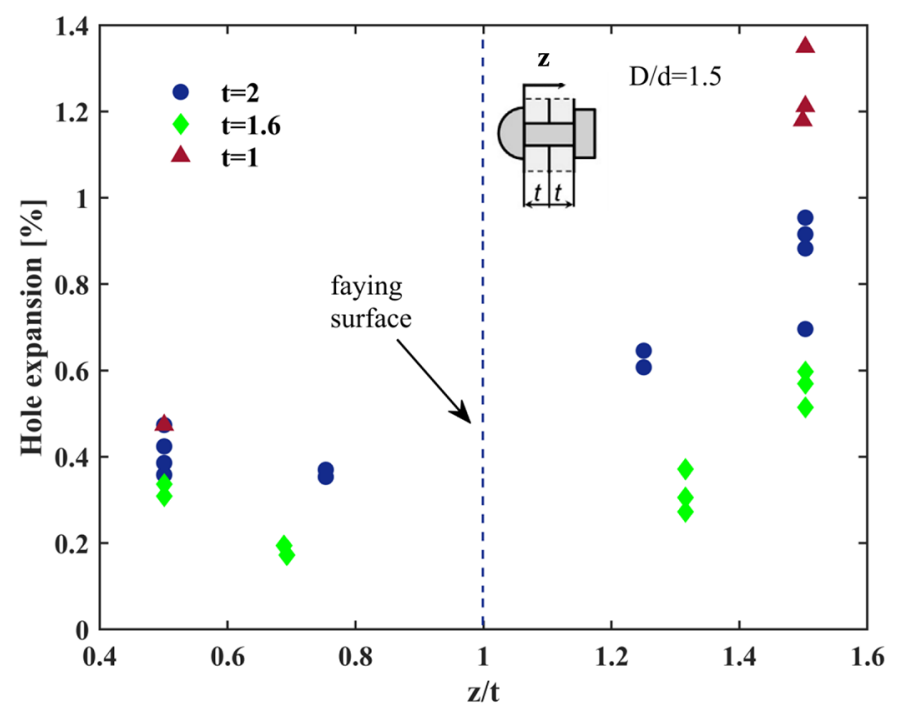

(b)

Fig. 10. (a, b) Effects of rivet sheets on the fatigue properties (a) specimen orientation [22] (b) sheet thickness [31].

\subsubsection{Squeeze force}

The squeeze force is a primary production variable influencing fatigue properties of riveted joints. The effect of squeeze force is mentioned in almost all studies on fatigue properties of riveted joints. Skorupa et al. [31] concluded that higher squeeze force can improve fatigue performance of joints by compensating for the adverse effect of friction between sheets. Similar conclusions have been drawn in other studies $[17,22]$. Figure 11 presents the relationship between corrected fatigue life with squeeze force for two types of riveted specimen configurations [36]. Zeng et al. [37] found that the boundary of the hardening zone at which the tangential stress turned into maximum tensile stress is also deemed responsible for such phenomenon that, the riveted lap joint may appear in different crack morphology and location under the fatigue load with

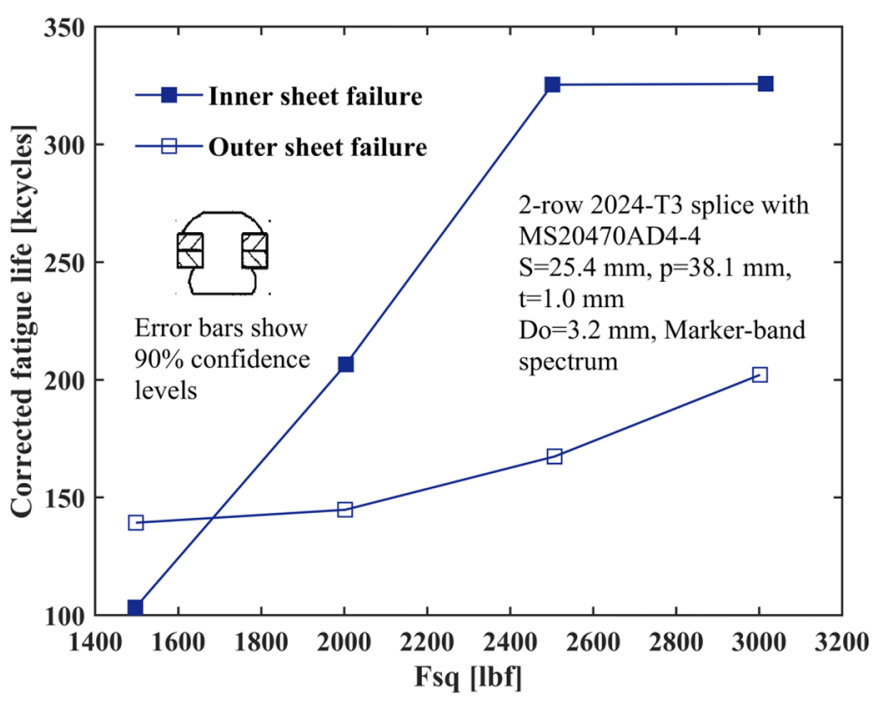

(a)

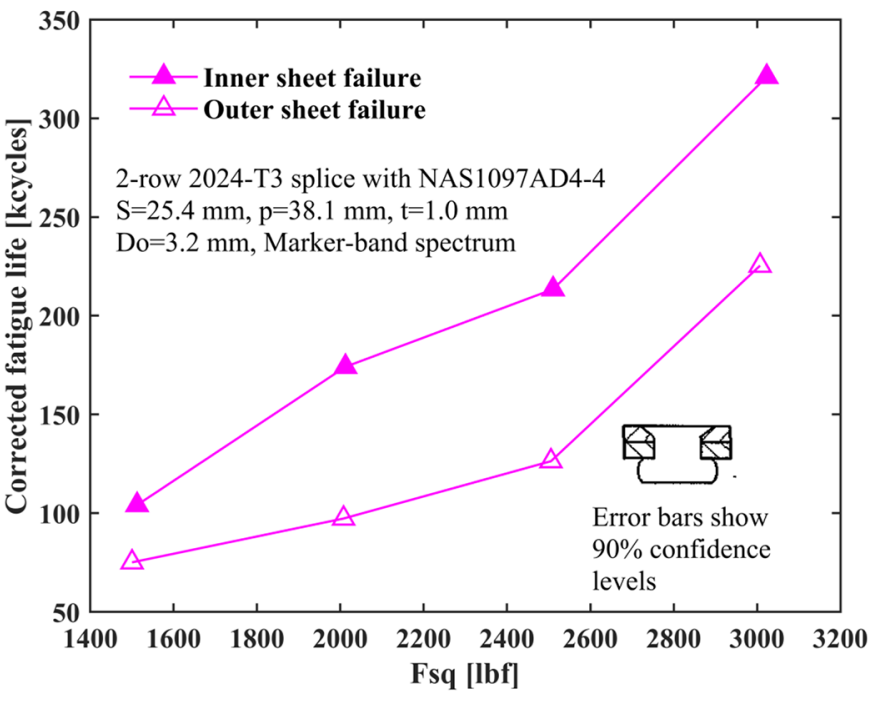

(b)

Fig. 11. Effect of squeeze force on fatigue life of two types of riveted specimen configurations. Where $D_{o}$ is rivet diameter, $s$ is rivet pitch, $t$ is sheet thickness, $p$ is row pitch [36]. (a) Universal joint. (b) Countersunk joint.

increasing squeeze force, thus explaining the fatigue problems of some joints.

\subsubsection{Interference-fit}

Interference fit is one of the important production variables to improve the fatigue life of riveted joints. The latest research is mainly aimed at the uniformity of interference fit, the mechanism of improving fatigue performance of interference fit and the influencing factors of interferencefit $[24,31,35,38]$. Skorupa et al. [31] found that the coefficients of interference between rivets and holes and friction between joints were linearly correlated with riveting parameters (mainly squeezing force). This linear relationship is effective for predicting the fatigue properties of joints. Zhou et al. [35] found that clamping the 
interference-fitted joint exhibits higher fatigue lives than that of clamping of the cold-expanded and interferencefitted joint at low stress levels, while at high stress levels, the results are opposite, which explains exactly the results obtained by Huan et al. [24], who concluded that the influence of interference-fit on fatigue properties of joints is closely related to the stress level. Skorupa et al. [38] concluded that the interference-fit between the rivet and the hole can effectively compensate for the notch effect under the axial loadings to improve fatigue properties of riveted joints. Zeng et al. [37] concluded that the long life characteristic of hole is due to interference fit and the compressive stress level would decrease with it moved further from the hole and eventually turned into tensile stress.

\subsubsection{Factors influencing fatigue damage \\ 4.2.3.1 Residual stress}

Residual stress is usually considered as the primary factor for fatigue failure analysis. Related research mainly focuses on the influence of residual stress on fatigue failure. Zhou et al. [35] found that the induced compressive residual stress reduced the peak tensile stress at the hole edge, thus contributing to delaying crack nucleation and reducing its fatigue criticality during cyclic deformation. In addition, the beneficial effects of strengthening techniques on the fatigue life are attributed to the reduction in maximum residual stress around the hole.

Various researches have been performed to control RS aiming to address fatigue problem, such as the influence of initial interference fit on residual stress [39], and the fatigue failure prediction method based on residual stress [40]. Zeng et al. [37] found that, an initial interference-fit is likely to introduce a high level of residual stress in the structure compared to a larger squeeze force. An explanation to the characteristics of fatigue crack under initial interference fit was given. However, it is difficult to draw a quantitative relationship between the cracks and the squeeze load, which depends on the complex mechanism of crack initiation and propagation in the presence of fretting damage under multiaxial fatigue loads. Ribeiro et al. [41] predicted residual stresses arising from cold expansion using two different finite element (FE) approaches, and compared the results to measurement data obtained by the contour method. The comparison results show that their residual stress prediction ability has been greatly improved.

\subsubsection{Transfer load}

The role of riveted joints is to transfer the load from one sheet to another sheet in the overlap region. The effects of load modes, rivets and expansion on load transfer and fatigue failure have been studied. Skorupa et al. [38] concluded that the mechanism of load transfer varies with load modes and the rivet of outer rivet rows plays an obvious role in the load transfer process of the joint. Skorupa et al. [42] concluded that the effect of both the squeeze force and the faying surface condition on load transfer through the outer rivet rows is quantitatively insignificant. In addition, the overall adverse effect of friction on load transfer has a negative impact on the fatigue properties of joints. Skorupa et al. [30] believed that the hole expansion increased the load transfer rate of the joint, which had a positive impact on the fatigue characteristics of the joint.

\subsubsection{Fretting}

Fretting influences fatigue properties of riveted joints, especially crack initiation site. The conducted research includes condition of joint surface, squeeze force, and the relationship between crack and fretting.

Skorupa et al. [31] concluded that fretting would make the wear worse after sheet cracks appear due to fretting, which has a greater negative impact on the fatigue properties of joints. A higher rivet squeeze force and a higher applied stress yielded an increased area of the fretted regions. Skorupa et al. [42] observed that fretting was always more severe in the outer rivet rows than in the middle row, around the rivets of the cracked row compared to the uncracked row, which indicates that the fatigue problem of the joint has a greater correlation with fretting. They also found that fragmentary profile measurements for the fretted regions did not show a dependency of the maximum height of the roughness profile on the squeeze force. However, the correlation between the wear area and the squeeze force was not clear. This does not mean that the level of squeeze force has no effect on fretting wear, but in fact, it has a direct impact.

\section{Solutions and limitations of current research on addressing failures in riveting}

\subsection{Static failure}

\subsubsection{Solutions}

Relevant research for the static strength failure of riveted joints were carried out mainly in standard, prediction model, service environment and hybird joints. The standards give a solution considering engineering application specific for engineering practice. The prediction model is a predictive solution for static failure of joints based on fundamental theory and analysis. The service environment is to study the failure mode of riveted joint investigating external factors. The hybrid joint is a solution improving static properities of riveted joints introducing a new connection mode.

- To address the static failure of metal riveted joints, relevant static strength design standards were formulated. Manes et al. [43] considered that the maximum static strength given on the rivets and on the hole (bearing loads) is the guiding criterion during the metallic material fastener design process.

- To predict the failure of riveted joints, the static strength characterisation technology of joints has been proposed, especially the semi-analytical prediction method based on practical engineering applications [20]. In these semianalytical models, residual stress, manufacturing varia- 
bles, and design parameters play dominant roles and should be taken into account comprehensively. Various experiences were obtained through experiments. For example, (1) the residual stress in the sheet due to expansion of the hole while setting the rivet has a significant effect on joint static strength [20]; (2) the squeezing force and tolerance compensate for reduced ultimate strength; (3) In addition, the ultimate strength reduction can amount to as much as $25 \%$ in some cases for the thinner sheets in FML accompanied by severe bearing deformation; (4) the role of rivet pull-through in the failure mode at small rations of sheet thickness to rivet diameter need to be paid more attentions.

- Besides the influence of the joint's factors, the external load is also considered as an important factor affecting the static strength performance of the joint. Li et al. [44] concluded that the total energy absorption of composite riveted joints increases with increasing loading rate.

- In some circumstances, single rivet strength is limited and unable to meet the strength requirement, hybrid joint technique was developed into structures connections. Chowdhury et al. [6] found that the benefits of hybrid joints outweigh those of bonded joints and riveted joints through series of experimental tests. In addition, they concluded that relatively thin structures lean towards using hybrid joint configurations particularly for repair scenarios.

Although prediction techniques, such as semi-analytical prediction model, have been introduced, there are still many limitations in the current static performance which are summarised as follows:

\subsubsection{Limitations}

- Current studies have been limited to the influence of squeeze force on the residual stress/strain distribution and SB stresses after rivet installation.

- The influence of squeeze force on joint static strength, load transmission, tendency of stress field around holes, and SB while tensile load applied is still not known entirely.

- Other influencing factors on static strength, such as SB and load transfer, in traditional riveting have not been in-depth studied.

- The investigation of newly developed riveted joints, that is, hybrid joint and electromagnetic joint, is not thorough in characterisation, influencing factors, riveted materials and riveting processes.

\subsection{Fatigue failure}

\subsubsection{Solutions}

Efforts were made on the key influencing factors on fatigue failure of joints, that is, design parameters, manufacturing variables, residual stresses, load transfer and fretting, to improve fatigue properties of riveted joints because these factors directly or indirectly produce different failure behaviour of joints, such as initiation, location of cracks, and propagation rate, which are detailed as follows:
- By optimising riveting design parameters, the fatigue properties of joints can be effectively improved, especially the failure behaviour of joints. For example, a large rivet row spacing or a smaller rivet spacing yields a higher fatigue strength of a lap joint $[28,45]$. Reducing the thickness of the sheets and increasing the distance between rivet rows lead to considerably longer fatigue lives [45].

- Production variables of riveted joints, especially squeeze force and riveting sequence, are the key factors affecting residual stress, SB, load transfer and fretting. Increasing squeeze force yields a longer fatigue life for joints with round head rivets regardless of the sheet thickness [43]. The fatigue performance of the joint can be improved by controlling the extrusion force and optimising the riveting sequence. Skorupa et al. [28] gave a dependency of rivet hole expansion and load transmission throughout the joint on the rivet squeeze force by the fatigue tests. The results found that the location and path of crack initiation were related to the level of squeeze force. The deformation of rivet due to local relatively great extent of material flow and typical compliant parts assembly, also affects fatigue properties of riveted joints. Optimisation of the riveting sequence of the structure was obtained to reduce riveting deformation $[46,47]$.

- Residual stress is the commonly used method to characterise fatigue failure of joints. Most of studies predict the residual stress of joints by establishing the relationship between squeeze force and residual stress. Zeng et al. [37] concluded that the initial fit was more likely to produce higher residual stress level compared with the larger squeeze force. Actually, it can be seen that the squeeze force affects the residual stress level through deduced interference fit. However, in practical production, interference fit can only be controlled by controlling squeeze force, and then residual stress level can be controlled.

- More methods have obtained better fatigue properties by increasing the load transfer rate by increasing the friction between sheets $[38,48,49]$. Direct measurements of frictional forces for bolted lap joints with instrumented bolts and experiments to indirectly estimate the friction contribution for riveted lap joints indicate that during fatigueloading, load transmission by friction initially increases with thecycle number until, after a certain portion of fatigue life, a stabilised level is attained. At this stage, up to $80-90 \%$ of the transferforce is transmitted by friction. The percentage of the applied load transferred by friction increases with the amount of clamping. They concluded that frictional force between the faying sheets can transfer load to relieve burden of joints to improve fatigue properties of riveted joints.

- Fretting is recognised as one of the major in the initiation of fatigue crack in riveted joints $[27,50-52]$. A correlation between the mount of fretting and the fatigue crack initiation site was studied to improve fatigue properties of joints. They found that a direct correlation of fretting with rivet hole cracking is not possible $[39,40,53-55]$. Hole crack is affected by loading and service environment. In addition, fretting is not a prerequisite for the onset of fatigue failure away from the hole edge $[19,27,56]$. 
Although a various of solutions have been proposed to address the fatigue problem, there still exist many limitations need to be overcome in the joint fatigue failure in future, as follows:

\subsubsection{Limitations}

- Quantification of relationship is still lacking. Traditional methods summarised a small part of the quantitative relationship between influencing factors and fatigue performance of riveted joints, but more systematic quantitative relationships are severely lacked, especially for new materials, new structures and new processes.

- The boundary conditions, such as frictional force at contact surface, sheets with crack, are not fully taken into account in the current FE simulation method of fatigue performance of riveted joints.

- The effect of local deformation on fatigue performance of riveted joints has not been in-depth studied.

Focusing on the current identified limitations in research, the next two sections give a detailed review and analysis of new techniques in the recent research of static and fatigue failure aiming to provide useful guidelines for future research.

\section{Research on new riveting techniques}

Driven by the requirements of high performance and lightweight, new structures, process and materials have been introduced into the assembly [51]. To enhance the strength of the joint, other connection methods, such as bonding, are integrated with riveting, which is the so-called hybrid joint [24]. In addition, electromagnetic riveting technology has been applied to solve the challenge posed by the introduction of titanium alloys and composite materials [46].

\subsection{New structure}

New structure refers to the hybrid joints, such as bondingriveted joints (see Fig. 12a). Compared with riveted joints, hybrid joints can provide additional benefits, such as continuous seal-ability, higher strength, higher stiffness and better anti-peeling and impact resistance [58]. As Figure $12 \mathrm{~b}$ shows, with the increase of applied load $(P)$, the failure process of riveted joints shows nonlinearity, and failure occurs only after the maximum load is reached. The capacity of adhesive bonding load-carrying is higher than riveting and shows a linear relationship with the load. However, the bonded joint fails directly after reaching the maximum load. In comparison, the loadcarrying capacity of hybrid joints is higher than that of riveted joints and bonding joint. After reaching the maximum load-carrying capacity, it does not fail directly and therefore owns the advantages of the two single types of joints.

Chaudhari et al. [59] concluded that the hybrid joints can withstand higher load compared with riveted joints
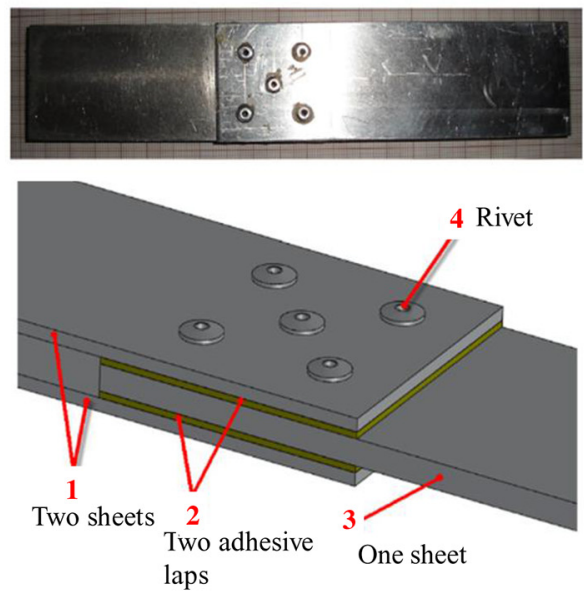

(a)

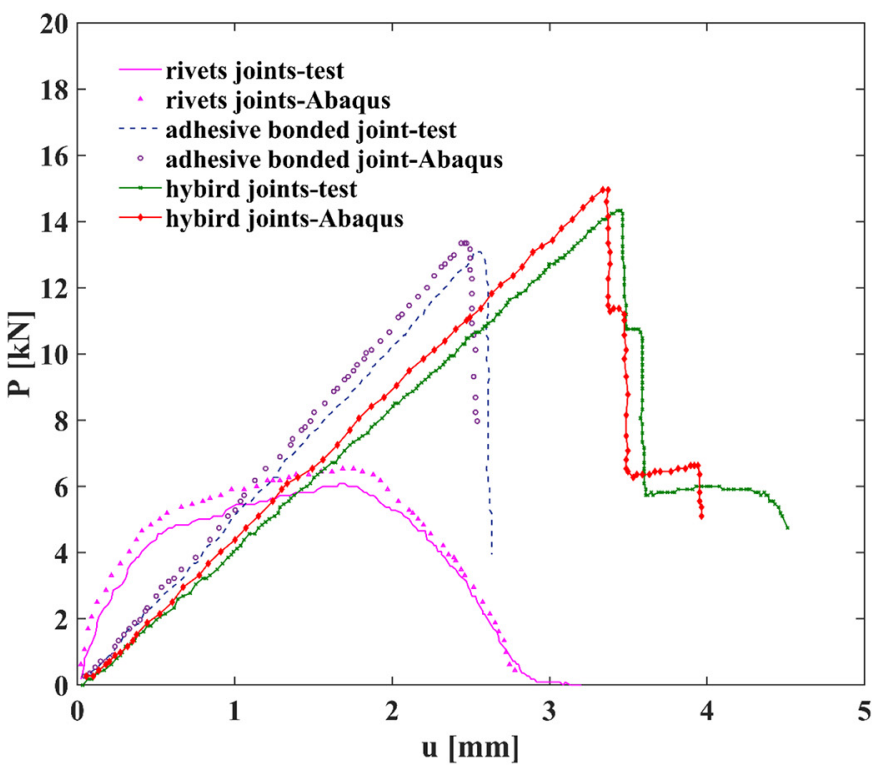

(b)

Fig. 12. Comparisons of force on the joint between conventional rivet and adhesive joints and hybrid joint [57]. (a) Practical example of hybrid joint. (b) Comparison of joining forces $(P)$ between hybrid joints and conventional joining techniques where $u$ is displacement of joints.

and adhesive bonding. The static strength performance of the hybrid joints after bonding is better than that of the single riveted joint. In addition, hybrid joints are more effective than the bonded joints in the maintenance of aircraft structures. Similar conclusion also can be found in the other literature [60].

Currently the application of hybrid joints is limited to the aircraft structural maintenance, and there are not many applications in aircraft assembly and manufacturing $[58,61]$. In addition, the influence factors of hybrid joints are less studied. Therefore, the research on the influencing factors of hybrid joints requires to be further investigated in future. 


\subsection{New process and materials}

Titanium alloys and composite materials have been introduced in aviation industry due to the high requirement of strength-weight ratio. The difficulty in forming new materials also brings challenges to riveting process. Electromagnetic riveting technology, especially low voltage portable electromagnetic riveting machine, has been developed rapidly and used widely [17].

Titanium alloys enable to significantly improve the static strength of riveted joints, so electromagnetic riveting technology is needed to achieve riveting forming considering that titanium alloy rivets are difficult to form [16]. EMR can also provide an adequate force for the formation of titanium rivets. In EMR, plastic deformation of titanium rivets is mainly concentrated at the shear band (see Fig. 13a), which is reported as the adiabatic shear band (ASB).

Due to the non-uniform interference, conventional riveting techniques are prone to cause serious bearing damage in composite structures during the formation of rivets (see Fig. 13b), which severely limits their application in joining composite structures. To reduce the damage, bolted joints instead of riveted joints are currently dominantly used in composite structures, unfortunately, leading to overweight structures and high costs. With the advantage of uniform interference, EMR allows composite structures to be riveted by reducing the riveting damage, which can obviously reduce the weight and cost of the joint. As shown in Figure 13b, the formations of rivet bars are uniform and no obvious damage is caused in CFRP during the EMR progress, which can lead to a high quality of riveted joints.

Zhang et al. [62] conducted electromagnetic riveting (EMR) tests with F6-mm titanium alloy rivets and analysed the static strength properties of the joints. Load curves of riveted structures for shear $/ 45^{\circ}$ pull-out tests are shown in Figure 14. The driven head with high speed deformations could bear $9.9 \mathrm{kN}$ shear loads and $12.5 \mathrm{kN}$ pull-out loads respectively. The EMR joints with multilayered sheets had higher interference-fit qualities. The EMR process can be used for difficult-to-deformation material rivets under the high efficiency, high quality and ambient temperature [62].

The static strength behaviour of joints with new materials and structures is investigated comprehensively. However, due to the introduction of new materials, new structures and new processes into riveting, the factors affecting the static strength of joints need to be quantitatively re-investigated.

\section{Summary \& future research}

\subsection{Summary}

Riveting technology in aviation has developed slowly compared to civil fields, such as automobile industry. The factor that can promote the development of riveting technology is material. In order to meet the requirements of materials, riveting technology needs to be improved, such

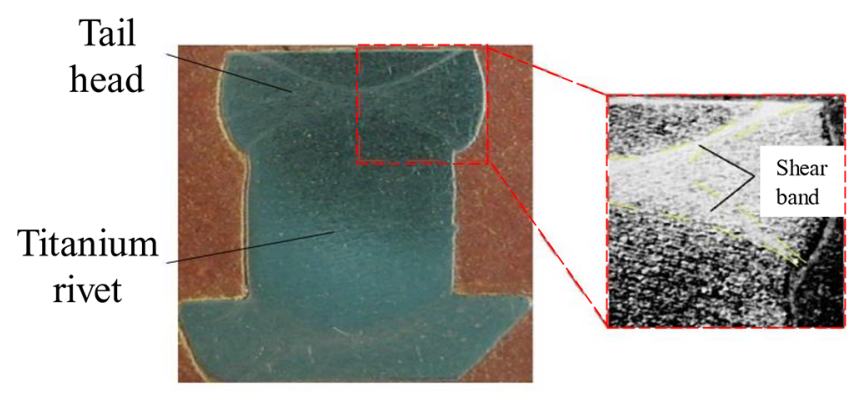

(a)

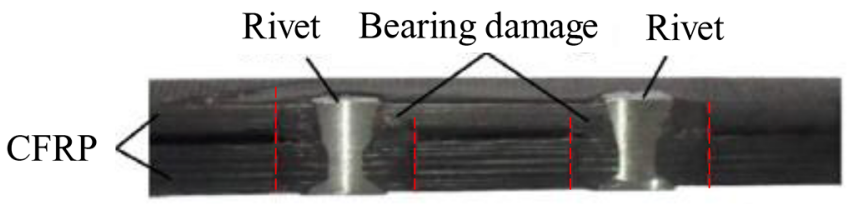

Riveted by conventional riveting technique

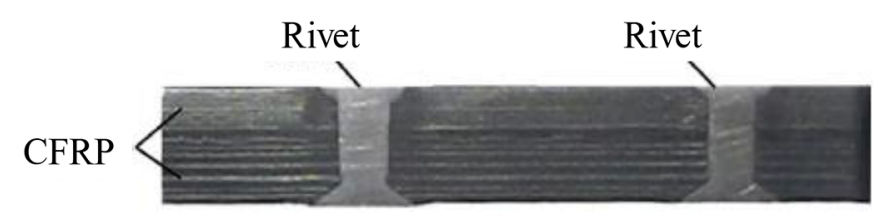

Riveted by the EMR technique

(b)

Fig. 13. (a,b) Applications of Electromagnetic Riveting in titanium and composite structures [16]. (a) titanium rivet (b) composite structure.

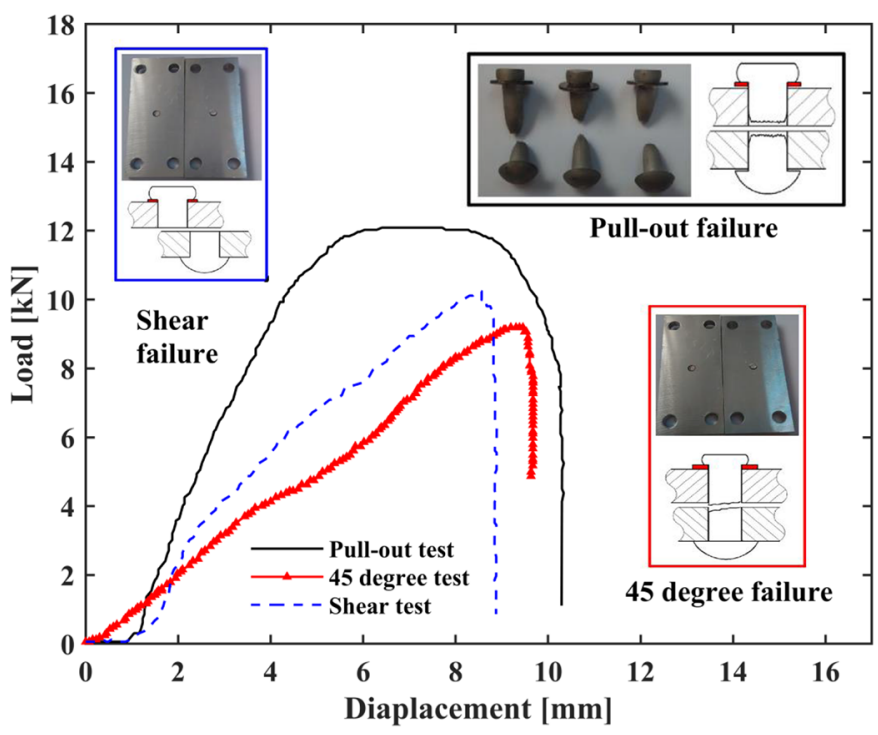

Fig. 14. The typical load-displacement for riveted structures and bolted structures [62].

as the introduction of composite materials and titanium alloys into aircraft industry, resulting in the great development of electromagnetic riveting technology and automatic riveting technology; Secondly, the urgent 
demand for riveting efficiency of aircraft structure, such as the emergence and application of low-voltage portable electromagnetic riveting machine; Thirdly, the introduction of new structures promotes the development of riveting technology, such as slug rivets. The introduction of riveting technology promotes the development of automatic drilling and riveting technology, etc. Based on the development of riveting technology, this paper discussed the problems in the development of riveting technology.

- Qualitative studies on various influencing factors of riveting, such as design parameters, manufacturing variables, load transfer, residual stress and SB, are mostly qualitative studies. These qualitative studies are relatively complete. However, quantitative studies on corresponding factors and static/fatigue strength are less due to many factors and the complexity of the influencing mechanism of factors on static/fatigue strength. Some quantitative studies are mostly carried out for specific materials, conditions and processes. In addition, some quantitative studies have introduced engineering experience, such as the semi-empirical joint fatigue performance prediction model, which provides a great engineering guidance for application, but the effect is limited compared with quantitative research.

- Riveting may cause embrittlement of the hole edge on sheets, which is only mentioned in some literatures, but the corresponding research methods are not given. There are few predictions and experimental results in this respect.

- With the introduce of new material, new rivet structure and new riveting technology into aircraft manufacturing and assembly, some new influencing factors, such as temperature factors, have also been introduced. The coupling effects of new factors and original riveting influencing factors have not been thoroughly investigated.

- In aircraft repair, hybrid joints, especially bondingriveted joints, are introduced into aircraft patches. The static/fatigue characteristics of hybrid joints need to be further studied. Especially, in the presence of bonding, the influence of riveting factors on the static/fatigue performance of joints has not been fully considered.

- Finite element modelling studies mostly focus on mesh refinement, integration of global and local simulation, and combination of finite element method and other methods. However, the non-uniform expansion along sheets thickness direction and elastic-plastic of rivets, etc. are not fully considered in the simulation.

\subsection{Future research}

Based on current riveting developments, future research efforts are likely to focus on (i) Quantitative relationship between riveting factors and static/fatigue performance of joints; (ii) static/fatigue performance characterisation of new materials and mixed materials including titanium alloy, fibre reinforced composite and metallic fibre laminate, under new riveted processing; (iii) the static/ fatigue characteristics of hybrid joints and (iv) modelling of the riveting process and behaviour of riveted lap joints.

Due to the complexity of the process and affecting mechanism of influencing factors, the modelling of riveting process and behaviour of riveted lap joints, and the quantitative relationship between riveting parameters and static/fatigue performance of joints remain the main challenges for the riveting research in aircraft applications.

The strong support from the Aviation Industry Corporation of China (AVIC) Aircraft Strength Research Institute (ASRI) for this funded research is much appreciated. The research was performed at the ASRI-Imperial Engineering Mechanics and Strength Programme at Imperial College London.

\section{References}

1. R. Humberto et al., Comparing mechanical behaviour of aluminium welds produced by laser beam welding (LBW), friction stir welding (FSW), and riveting for aeronautical structures, Weld. Int. 30 (2016) 497-503

2. J.L. Rumpf, The ultimate strength of bolted connections, PhD Thesis, Lehigh University, 1960

3. S. Pantelakis, K.I. Tserpes, Adhesive bonding of composite aircraft structures: challenges and recent developments, Sci. China Phys. Mech. Astron. 57 (2014) 2-11

4. X. He, A review of finite element analysis of adhesively bonded joints, Int. J. Adhes. Adhes. 31 (2011) 248-264

5. A. Higgins, Adhesive bonding of aircraft structures, Int. J. Adhes. Adhes. 20 (2000) 367-376

6. N. Chowdhury, W.K. Chiu, J. Wang, P. Chang, Static and fatigue testing thin riveted, bonded and hybrid carbon fiber double lap joints used in aircraft structures, Compos. Struct. 121 (2015) 315-323

7. A. Atre, A finite element and experimental investigation on the fatigue of riveted lap joints in aircraft applications. $\mathrm{PhD}$ Thesis, Georgia Institute of Technology, 2006

8. V. Psyk, D. Risch, B.L. Kinsey, A.E. Tekkaya, M. Kleiner, Electromagnetic forming - a review, J. Mater. Process. Technol. 211 (2011) 787-829

9. Q. Collette, Riveted connections in historical metal structures (1840-1940) PhD Thesis, Vrije Universiteit Brussel, 2014

10. R.D. Mott, Effect of panel inertia and stiffness on rivet formation rate during percussive riveting, MASc Thesis, University of Washington, 2018

11. S. Behrning, H. Bley, S. Joergens, Innovative high-performance process for dry manufacturing of sheet metal armatures and their integrated on-line cleanliness examination, J. Mater. Process. Technol. 115 (2001) 25-30

12. Y. Zuo, Z. Cao, L. Yang, C. Zang, Interfrence-fit evenness riveting method based on symmetrical loading, Acta Aeronatica Astronaut. Sin. 37 (2016) 1049-1059

13. Z. Cao, M. Cardew-Hall, Interference-fit riveting technique in fiber composite laminates, Aerosp. Sci. Technol. 10 (2006) 327-330

14. E.E. Brown, O.F. Streatham, Metal spar or girder for aircraft, 1920 
15. W. Tian, Z. Zhou, W. Liao, Analysis and investigation of a rivet feeding tube in an aircraft automatic drilling and riveting system, Int. J. Adv. Manuf. Technol. 82 (2016) 973-983

16. Z. Cao, Y. Zuo, Electromagnetic riveting technique and its applications, Chinese J. Aeronaut. 33 (2020) 5-15

17. C. Lei, Y. Bi, J. Li, Y. Ke, Effect of riveting parameters on the quality of riveted aircraft structures with slug rivet, Adv. Mech. Eng. 9 (2017) 1-12

18. X. Zhang, H.P. Yu, J. Li, C.F. Li, Microstructure investigation and mechanical property analysis in electromagnetic riveting, Int. J. Adv. Manuf. Technol. 78 (2015) 613-623

19. M. RPG, An experimental and analytical investigation on the fatigue behaviour of fuselage riveted lap joints, $\mathrm{PhD}$ Thesis, Delft University of technology, 1995

20. W.J. Slagter, Static strength of riveted joints in fibre metal laminates, PhD Thesis, Delft University of Technonloy, 1994

21. P.M.S.T. de Castro, P.F.P. de Matos, P.M.G.P. Moreira, L.F.M. da Silva, An overview on fatigue analysis of aeronautical structural details: open hole, single rivet lap-joint, and lap-joint panel, Mater. Sci. Eng. A 468-470 (2007) 144-157

22. A. Skorupa, M. Skorupa, Riveted Lap Joints in Aircraft Fuselage: Design, Analysis and Properties. Springer Science, London and Business Media Dordrecht, Dordrecht, 2012

23. de R. JJM, Stress analysis of fatigue cracks in mechanically fastened joints, $\mathrm{PhD}$ Thesis, Delft University of Technology, 2005

24. H. Huan, M. Liu, Effects of squeeze force on static behavior of riveted lap joints, Adv. Mech. Eng. 9 (2017) 1-13

25. C. Dechwayukul, C.A. Rubin, G.T. Hahn, Analysis of the effects of thin sealant layers introduction, AIAA J. 41 (2003) $2216-2228$

26. P. Linde, H. de Boer, Modelling of inter-rivet buckling of hybrid composites, Compos. Struct. 73 (2006) 221-228

27. G. Harish, T. Farris, An integrated approach for prediction of fretting crack nucleation in riveted lap joints, 40th Struct. Struct. Dyn. Mater. Conf. Exhib. (1999) 1219-1226

28. A. Skorupa, M. Skorupa, T. Machniewicz, A. Korbel, Fatigue crack location and fatigue life for riveted lap joints in aircraft fuselage, Int. J. Fatigue 58 (2014) 209-217

29. C.D. Rans, The role of rivet installation on the fatigue performance of riveted lap joints, $\mathrm{PhD}$ Thesis, Carleton University, 2007

30. M. Skorupa, T. Machniewicz, A. Skorupa, J. Schijve, A. Korbel, Fatigue life prediction model for riveted lap joints, Eng. Fail. Anal. 53 (2015) 111-123

31. M. Skorupa, T. Machniewicz, A. Skorupa, A. Korbel, Fatigue life predictions for riveted lap joints, Int. J. Fatigue 94 (2017) $41-57$

32. Y. Tong, L. Qu, Recent patents in riveting and applications, Recent Patents Eng. 3 (2009) 220-227

33. C. Lei, Y. Bi, J. Li, Y. Ke, Slug rivet assembly modeling and effects of procedure parameters on the quality of riveted lap joints, Adv. Mech. Eng. 10 (2018) 1-12

34. J. Cui, L. Qi, H. Jiang, G. Li, X. Zhang, Numerical and experimental investigations in electromagnetic riveting with different rivet dies, Int. J. Mater. Form. 11 (2018) 839-853

35. B. Zhou et al.,Experimental investigation and finite element analysis on fatigue behavior of aluminum alloy 7050 singlelap joints, J. Mater. Eng. Perform. 27 (2018) 915-923
36. B.E. and M.A. Sc, The Role of Rivet Installation on the Fatigue Performance of Riveted Lap Joints, no. August. 2007

37. C. Zeng, W.H. Liao, W. Tian, Influence of initial fit tolerance and squeeze force on the residual stress in a riveted lap joint, Int. J. Adv. Manuf. Technol. 81 (2015) 1643-1656

38. M. Skorupa, T. Machniewicz, A. Skorupa, A. Korbel, Fatigue strength reduction factors at rivet holes for aircraft fuselage lap joints, Int. J. Fatigue 80 (2015) 417-425

39. A. Brown, An examination of faying surface fretting in single lap splices, PhD Thesis, Carleton University, 2008

40. M.P. Szolwinski, The mechanics and tribology of fretting fatigue with application to riveted lap joints, $\mathrm{PhD}$ Thesis, Purdueuniversity, 1998

41. R.L. Ribeiro, M.R. Hill, Residual stress from cold expansion of fastener holes: measurement, eigenstrain, and process finite element modeling, J. Eng. Mater. Technol. (2017)

42. M. Skorupa, T. MacHniewicz, A. Skorupa, A. Korbel, Effect of load transfer by friction on the fatigue behaviour of riveted lap joints, Int. J. Fatigue 90 (2016) 1-11

43. A. Manes, M. Giglio, F. Vigan, Effect of riveting process parameters on the local stress field of a T-joint, Int. J. Mech. Sci. 53 (2011) 1039-1049

44. Q.M. Li, R.A.W. Mines, R.S. Birch, Static and dynamic behaviour of composite riveted joints in tension, Int. J. Mech. Sci. 43 (2001) 1591-1610

45. M. Skorupa, A. Korbel, A. Skorupa, T. Machniewicz, Observations and analyses of secondary bending for riveted lap joints, Int. J. Fatigue 72 (2015) 1-10

46. H. Wang, Riveting sequence study of horizontal stabilizer assembly using finite-element analysis and riveting equivalent unit, J. Aerosp. Eng. 27 (2014) 04014040

47. G.F. Abdelal, G. Georgiou, J. Cooper, A. Robotham, A. Levers, P. Lunt, Numerical and experimental investigation of aircraft panel deformations during riveting process, J. Manuf. Sci. Eng. 137 (2015) 011009

48. J. Schijve, G. Campoli, A. Monaco, Fatigue of structures and secondary bending in structural elements, Int. J. Fatigue 31 (2009) 1111-1123

49. D.A. Cope, T.E. Lacy, Modeling mechanical fasteners in single-shear lap joints, J. Aircr. 41 (2004) 1491-1497

50. P.I. Hurricks, The mechanism of fretting - a review, Wear 15 (1970) 389-409

51. K. Iyer, G.T. Hahn, P.C. Bastias, C.A. Rubin, Analysis of fretting conditions in pinned connections, Wear 181-183 (1995) 524-530

52. K. Iyer, C.A. Rubin, G.T. Hahn, Influence of interference and clamping on fretting fatigue in single rivet-row lap joints, J. Tribol. 123 (2001) 686

53. S. Piascik, A. Willard, The characterization of widespread fatigue damage in fuselage structure, 1994

54. R. Guo, R.C. Duan, G. Mesmacque, L. Zhang, A. Amrouche, R. Guo, Fretting fatigue behavior of riveted $\mathrm{Al}$ 6XXX components, Mater. Sci. Eng. A 483-484 (2008) 398-401

55. H. Ganapathy, T.N. Farris, Modeling of skin/rivet contact: application to fretting fatigue, Am. Inst. Aeronaut. Astronaut. 4 (1997) 2761-2771

56. K.D. Van, N. Maouche, An analysis of fretting-fatigue failure combined with numerical calculations to predict crack nucleation, Wear 181-183 (1995) 101-111 
57. T. Sadowski, P. Golewski, Damage and failure processes of hybrid joints: Adhesive bonded aluminium plates reinforced by rivets, Comput. Mater. Sci. 50 (2011) $1256-1262$

58. E. Armentani, R. Citarella, DBEM and FEM analysis on non-linear multiple crack propagation in an aeronautic doubler-skin assembly, Int. J. Fatigue 28 (2006) 598-608

59. S.P. Chaudhari, Comparison of static analysis of bonded, riveted and hybrid joints by using different materials, Int. J. Innov. Res. Sci. Technol. 4 (2018) 55-63
60. S. Pitta, V. de la Mora Carles, F. Roure, D. Crespo, J.I. Rojas, On the static strength of aluminium and carbon fibre aircraft lap joint repairs, Compos. Struct. 201 (2018) 276-290

61. M. Saadat, R. Sim, F. Najafi, Modelling and analysis of Airbus wingbox assembly, Proc. Inst. Mech. Eng. B J. Eng. Manuf. 222 (2008) 701-709

62. X. Zhang, M. Zhang, L. Sun, C. Li, Numerical simulation and experimental investigations on TA1 titanium alloy rivet in electromagnetic riveting, Arch. Civ. Mech. Eng. 18 (2018) 887-901

Cite this article as: Hongwei Zhao, Jiangjing Xi, Kailun Zheng, Zhusheng Shi, Jianguo Lin, Kamran Nikbin, Shihui Duan, Binwen Wang, A review on solid riveting techniques in aircraft assembling, Manufacturing Rev. 7, 40 (2020) 